\title{
Development of Pavement Distress Deterioration Prediction Models for Urban Road Network Using Genetic Programming
}

\author{
Tanuj Chopra (D), ${ }^{1}$ Manoranjan Parida, ${ }^{2}$ Naveen Kwatra, ${ }^{1}$ and Palika Chopra ${ }^{3}{ }^{3}$ \\ ${ }^{1}$ Department of Civil Engineering, Thapar University, Patiala, India \\ ${ }^{2}$ Department of Civil Engineering, Indian Institute of Technology, Roorkee, India \\ ${ }^{3}$ Department of Computer Science and Engineering, Thapar University, Patiala, India \\ Correspondence should be addressed to Tanuj Chopra; tchopra@thapar.edu
}

Received 23 August 2017; Revised 5 December 2017; Accepted 14 December 2017; Published 29 March 2018

Academic Editor: Francesco Canestrari

Copyright (C) 2018 Tanuj Chopra et al. This is an open access article distributed under the Creative Commons Attribution License, which permits unrestricted use, distribution, and reproduction in any medium, provided the original work is properly cited.

\begin{abstract}
The objective of the present study is to develop models to predict the deterioration of pavement distress of the urban road network. Genetic programming (GP) has been used to develop five models for the prediction of pavement distress: Model 1 for the cracking progression, Model 2 for the ravelling progression, Model 3 for the pothole progression, Model 4 for the rutting progression, and Model 5 for the roughness progression. The data have been collected from the roads of Patiala City, Punjab, India; during the years 2012-2015, the network of 16 roads have been selected for the data collection purposes. The data have been divided into two sets, that is, training dataset (data collected during the years 2012 and 2013) and validation dataset (data collected during the years 2014 and 2015). The two fitness functions have been used for the evaluation of the models, that is, coefficient of determination $\left(R^{2}\right)$ and root mean square error (RMSE), and it is inferred that GP models predict with high accuracy for pavement distress and help the decision makers for adequate and timely fund allocations for preservation of the urban road network.
\end{abstract}

\section{Introduction}

India's road network is the second largest in the world, with the total road length increased from 0.399 million kilometers as on 31 March 1951 to 4.698 million kilometers as on 31 March 2011 [1]. The urban roads clutch huge traffic and bear the economic loss due to poor condition of the roads that accumulates to a gigantic sum. The total transportation cost comprised two basic components, that is, road cost and user cost. Researcher's studies $[2,3]$ on various aspects of road pavement and transportation have indicated that the road user cost constitutes a major part (around $80-90 \%$ of the total transportation cost) which could be saved substantially with the help of a good decision support system. The utilization of urban roads and problems faced while maintenance are totally different than highway road network. In urban roads, the trip length is small, the number of trips and diversion is large, and the intensity of traffic is heavy and nonuniform. In the last twenty years, the maintenance management systems have improved significantly due to the advances in technologies. Many researchers are working on the development of pavement maintenance management system (PMMS) and the effect of road surface deformations [4-17]. PMMS is one of such tools that assist engineers to maintain the roads in their serviceable conditions [17]. Mathew et al. [18] made efforts to develop the deterioration models for performance of rural roads using artificial neural network (ANN) and compared with regression techniques. They concluded that an ANN model proved to be more suitable than the conventional regression models because of its ability to adjust to a changing environment. Fwa et al. [19] presented a genetic algorithm(GA-) based procedure for solving multiobjective network level pavement maintenance programming problems. They adopted the concepts of Pareto optimal solution set and rank-based fitness evaluation and two methods for selecting an optimal solution. Chan et al. [20] applied GA for optimizing the resource allocation for pavement maintenance programming. They also compared the performance of the various constraint handling methods, namely, prioritized resource allocation method, decode-repair method, and penalty method. Terzi [21] used ANN in modeling the 
Pavement Service Rating (PSR) for the flexible pavements. They developed an ANN model using input variables which were longitudinal cracking, total cracking, patching, rut depth, slope variance, and output as panel data of PSR. The model was trained and tested using 74 datasets obtained from AASHO test results. The comparison of PSR had been done with the ANN model and PCI had been obtained from AASHO equation. The values of coefficient of determination $\left(R^{2}\right)$ for the ANN model were 0.83 and 0.82 for the training set and testing set, respectively, and for PSI, the values of $R^{2}$ were 0.99 and 0.87 for the training and testing set, respectively. Reddy and Veeraragavan [22] developed deterioration models and growth curves for rebound deflection, rut depth, and crack area for two types of pavement surfacing. They developed predictive models for deflection, rut depth, and crack area progression with traffic. Bianchini and Bandini [23] proposed a neurofuzzy model to predict the performance of flexible pavements using the parameters routinely collected by agencies to characterize the condition of an existing pavement. Their proposed hybrid model for predicting pavement performance was characterized by multilayer feed-forward neural networks that led the reasoning process of the IFTHEN fuzzy rules. Khraibani et al. [24] presented a nonlinear mixed-effects model for the evaluation and prediction of pavement deterioration. Luo [25] proposed the application of an auto regression method to pavement performance modeling to improve the predictive accuracy of predictions when there are only limited or incomplete data available.

The literature reveals that there is successful implementation of PMMS for maintaining the road network and making optimal use of resources in developed countries. However, still attempts are made to transfer such systems to developing countries from developed ones based on techniques, methodologies, and resources that are improper to local condition [26]. Successful implementation of PMMS for different road categories in developing countries like India will lead to optimal use of resources and better and safer roads. The objective of the present study is to develop models for urban road network of Patiala (Punjab, India) using genetic programming (GP) to predict the pavement distress deterioration.

\section{Data Collection}

An efficient decision support system depends on accuracy, integrity, reliability, and the most important completeness of the database. The data have been collected on the selected 16 roads of Patiala, and the database has been organized in such a manner that the data will be retrieved easily. A detailed description of the collected data and the procedure of data collection and equipments used for the PMMS have been presented in the subsections.

\subsection{Identification and Selection of Patiala City Road} Sections. The very first step is to identify the road network and select the road sections. In the present study, Patiala City (Punjab, India) road network has been identified and 16 road sections have been selected for developing pavement distress models. Figure 1 shows a map of urban road networks of Patiala city, and Table 1 consists of inventory data of selected road sections. The selected road sections are homogeneous within them but vary considerably from each other in terms of traffic and pavement width.

2.2. Traffic Volume Data. In the present study, traffic volume data have been collected from Municipal Corporation, Patiala. Table 2 consists of the traffic volume of each road section, and Table 3 shows volume-to-capacity ratio of the selected road network. The Equivalent Standard Axle (ESA) repetition in the analysis year (in millions) has been calculated as per IRC 37 [31].

2.3. Structural Evaluation of Pavements. The structural evaluation has been undertaken to assess the pavement's structural ability to receive wheel loads plying over it, that is, measurement of rebound deflection. The normal practice is to use the Benkelman beam deflection (BBD) method for evaluating the structural condition of the flexible pavement as per the procedure laid down in IRC [27]. The dual rear wheels of the truck are centered above the selected point. The probe of the Benkelman beam is inserted between the dual wheels and placed on the selected point. The initial reading $\left(D_{0}\right)$ is recorded when the rate of deformation of the pavement is equal or less than $0.025 \mathrm{~mm} /$ minute. The truck is slowly driven a distance of $2.70 \mathrm{~m}$. An intermediate reading $\left(D_{\mathrm{i}}\right)$ is recorded when the rate of recovery of the pavement is equal or less than $0.025 \mathrm{~mm} /$ minute. The truck is driven forward a further $9 \mathrm{~m}$. The final reading $\left(D_{\mathrm{f}}\right)$ is recorded when the rate of recovery of pavement is equal to or less than $0.025 \mathrm{~mm} /$ minute. The rebound deflections have been calculated for all the selected road sections by taking the initial, intermediate, and final deflection readings of the BBD test. The rebound deflection value at any point is given by the following two conditions:

(i) If $\left(D_{\mathrm{i}}-D_{\mathrm{f}}\right) \leq 0.025 \mathrm{~mm}$, then rebound deflection $=2\left(D_{0}-D_{\mathrm{f}}\right)$.

(ii) If $\left(D_{\mathrm{i}}-D_{\mathrm{f}}\right)>0.025 \mathrm{~mm}$, then rebound deflection $=2\left(D_{0}-D_{\mathrm{f}}\right)+2.91$ [2 $\left.\left(D_{\mathrm{i}}-D_{\mathrm{f}}\right)\right]$.

Pavement temperature has been recorded at least once every hour by inserting thermometer in the standard hole and filling up the hole with glycerol. The rear axle weight of the truck is $8170 \mathrm{~kg}$ with a tyre pressure of $5.6 \mathrm{~kg} / \mathrm{cm}^{2}$, and spacing between the tyre walls is $35 \mathrm{~mm}$. Test points are taken at a distance of $60 \mathrm{~cm}$ from the pavement edge if the lane width is less than $3.5 \mathrm{~m}$ and at $90 \mathrm{~cm}$ distance from the pavement edge for wider lanes. For divided four lane stretch, the measurement points should be at a distance of $1.5 \mathrm{~m}$ from the pavement edge. Since the deflections measured by the Benkelman beam (BB) are influenced by the pavement temperature and seasonal variations in different climates, pavement temperature and soil subgrade details have also been collected at all observation points for making subsequent corrections to the deflection values. The characteristic deflection value is obtained as a sum of the mean and standard 


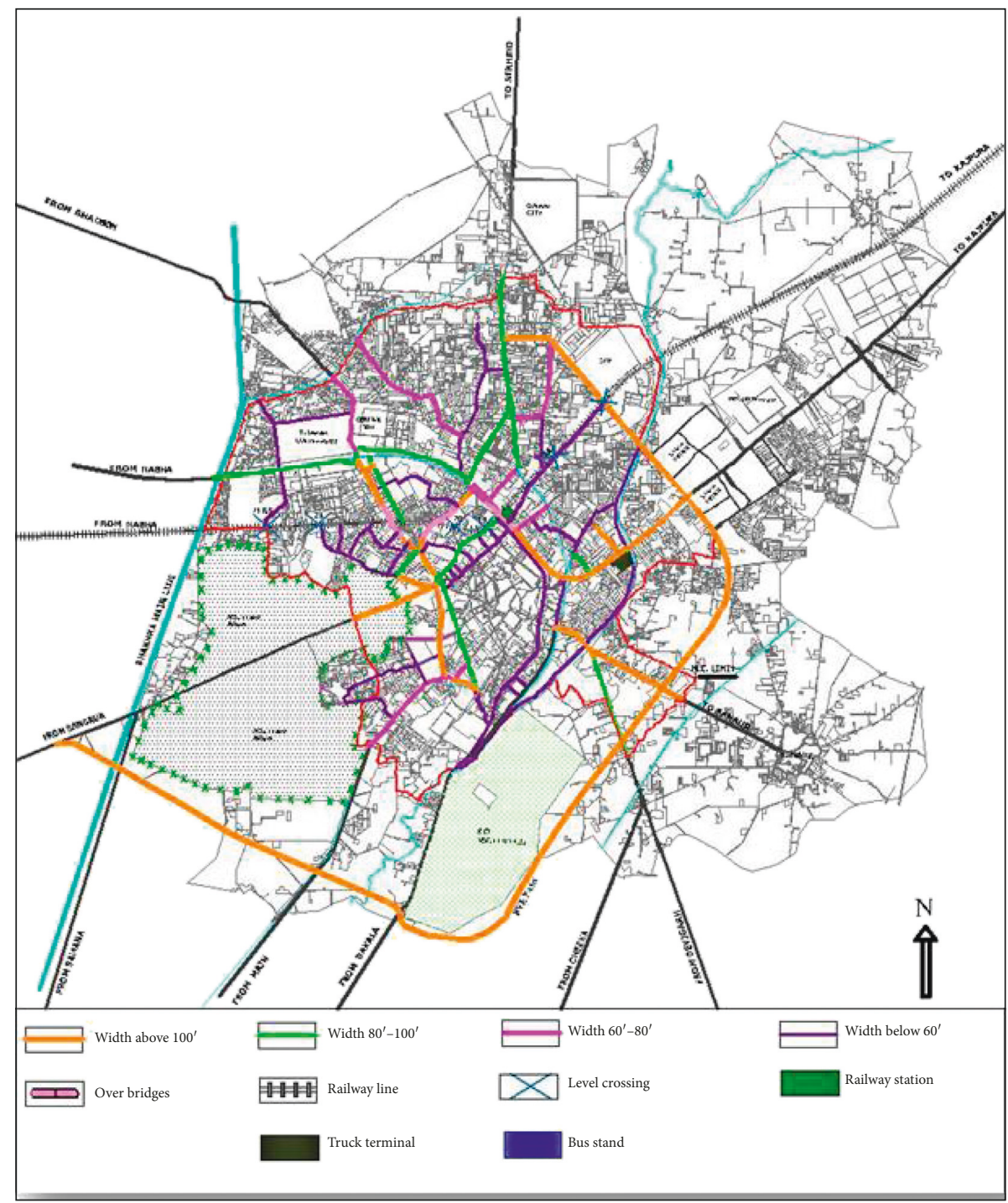

Figure 1: Map of Patiala (Punjab, India) urban road network.

TABLE 1: Inventory data of selected road sections.

\begin{tabular}{|c|c|c|c|c|}
\hline Section ID & Name of the road & $\begin{array}{c}\text { Length } \\
\text { (in kilometers) }\end{array}$ & $\begin{array}{l}\text { Width of the carriageway } \\
\text { (in meters) }\end{array}$ & $\begin{array}{l}\text { Drainage } \\
\text { condition }\end{array}$ \\
\hline UR01 & Thapar University-Bhadson Road & 0.80 & 6.80 & Fair \\
\hline UR02 & Thapar University-Bhupindra Road & 1.05 & 7.30 & Fair \\
\hline UR03 & Thapar University-Gurudwara Sahib (Passey Road) & 2.50 & 7.50 & Good \\
\hline UR04 & Passey Road-Civil Line (Ghuman Road) & 1.00 & 7.20 & Very poor \\
\hline UR05 & Gurudwara Sahib Chowk-Sirhind Road & 2.25 & 7.00 & Good \\
\hline UR06 & Leela Bhawan Chowk-Cantonment & 0.70 & 11.50 & Good \\
\hline UR07 & Gurudwara Sahib Chowk-Bus Stand Road & 0.90 & 7.50 & Poor \\
\hline UR08 & Thikriwala Chowk-Sangrur Road & 1.00 & 7.50 & Good \\
\hline UR09 & Thikriwala Chowk-Badungar Road & 0.80 & 11.80 & Fair \\
\hline UR10 & Bus Stand Chowk-Gurbax Colony & 2.10 & 6.0 & Poor \\
\hline UR11 & Fountain Chowk-Leela Bhawan & 0.70 & 12.5 & Good \\
\hline UR12 & Fountain Chowk-Lower Mall & 2.25 & 7.5 & Fair \\
\hline UR13 & Thapar University-Gurudwara Sahib & 2.25 & 7.30 & Fair \\
\hline UR14 & Leela Bhawan Chowk-No. 22 bridge & 2.10 & 7.50 & Good \\
\hline UR15 & Leela Bhawan Chowk-Gurudwara Sahib (Rajbaha Road) & 1.46 & 10.0 & Fair \\
\hline UR16 & Leela Bhawan Chowk-Baradari Garden & 1.10 & 6.40 & Good \\
\hline
\end{tabular}


TABle 2: Traffic volume data of road sections.

\begin{tabular}{|c|c|c|c|c|c|c|c|c|}
\hline Section ID & Cycle & Rickshaw/rehri & Scooter/M-cycle & Car/jeep/auto & Bus/truck/tractor/trolly & Cart & Total & $\begin{array}{c}\text { ESA in the year } 2013 \\
\text { (in millions) }\end{array}$ \\
\hline \multirow{2}{*}{ UR01 } & 198 & 118 & 350 & 371 & 112 & 22 & 1171 & \multirow{2}{*}{0.281} \\
\hline & 16.9 & 10 & 30 & 31.7 & 9.6 & 1.8 & 100 & \\
\hline \multirow{2}{*}{ UR02 } & 234 & 73 & 552 & 285 & 33 & 5 & 1182 & \multirow{2}{*}{0.072} \\
\hline & 19.8 & 6.2 & 46.7 & 24.1 & 2.8 & 0.4 & 100 & \\
\hline \multirow{2}{*}{ UR03 } & 152 & 141 & 341 & 285 & 78 & 5 & 1002 & \multirow{2}{*}{0.112} \\
\hline & 15.2 & 14.07 & 34.03 & 28.44 & 7.8 & 0.5 & 100 & \\
\hline \multirow{2}{*}{ UR04 } & 108 & 18 & 251 & 115 & 10 & 3 & 505 & \multirow{2}{*}{0.194} \\
\hline & 21.7 & 3.5 & 49.7 & 22.7 & 1.9 & 0.6 & 100 & \\
\hline \multirow{2}{*}{ UR05 } & 110 & 69 & 272 & 317 & 120 & 12 & 900 & \multirow{2}{*}{0.424} \\
\hline & 12.2 & 7.66 & 30.2 & 35.2 & 13.3 & 1.44 & 100 & \\
\hline \multirow{2}{*}{ UR06 } & 251 & 180 & 547 & 265 & 33 & 4 & 1280 & \multirow{2}{*}{0.144} \\
\hline & 20 & 14 & 42 & 21 & 2.6 & 0.4 & 100 & \\
\hline \multirow{2}{*}{ UR07 } & 267 & 201 & 584 & 535 & 129 & 15 & 1731 & \multirow{2}{*}{0.230} \\
\hline & 15.4 & 11.6 & 33.7 & 31 & 7.4 & 0.9 & 100 & \\
\hline \multirow{2}{*}{ UR08 } & 191 & 207 & 651 & 880 & 425 & 3 & 2357 & \multirow{2}{*}{0.127} \\
\hline & 8.1 & 8.8 & 27.61 & 37.34 & 18.03 & 0.12 & 100 & \\
\hline \multirow{2}{*}{ UR09 } & 171 & 158 & 470 & 338 & 29 & 2 & 1168 & \multirow{2}{*}{0.225} \\
\hline & 15 & 14 & 40 & 28.4 & 2.5 & 0.1 & 100 & \\
\hline \multirow{2}{*}{ UR10 } & 407 & 459 & 1104 & 65 & 5 & - & 2040 & \multirow{2}{*}{0.129} \\
\hline & 20 & 22.5 & 54.1 & 3.2 & 0.2 & - & 100 & \\
\hline \multirow{2}{*}{ UR11 } & 583 & 247 & 705 & 864 & 438 & 5 & 2842 & \multirow{2}{*}{0.166} \\
\hline & 21 & 9 & 25 & 29.8 & 15 & 0.2 & 100 & \\
\hline \multirow{2}{*}{ UR12 } & 464 & 358 & 722 & 878 & 34 & 12 & 2468 & \multirow{2}{*}{0.036} \\
\hline & 19 & 14.5 & 29 & 35.6 & 1.4 & 0.5 & 100 & \\
\hline \multirow{2}{*}{ UR13 } & 404 & 92 & 548 & 347 & 196 & 5 & 1592 & \multirow{2}{*}{0.902} \\
\hline & 25.4 & 5.8 & 34.4 & 21.8 & 12.3 & 0.3 & 100 & \\
\hline \multirow{2}{*}{ UR14 } & 554 & 349 & 1275 & 1106 & 112 & 8 & 3404 & \multirow{2}{*}{0.115} \\
\hline & 16.3 & 10.2 & 37.5 & 32.5 & 3.3 & 0.2 & 100 & \\
\hline UR15 & 381 & 319 & 1427 & 1179 & 714 & 20 & 4040 & 0928 \\
\hline UKIS & 9.4 & 7.6 & 35.2 & 29.2 & 17.6 & 1 & 100 & 0.928 \\
\hline & 371 & 180 & 580 & 144 & 2 & 3 & 1280 & \\
\hline UR16 & 29 & 14 & 45.3 & 11.3 & 0.15 & 0.25 & 100 & 0.003 \\
\hline
\end{tabular}

TABLE 3: Volume-to-capacity ratio of selected road network.

\begin{tabular}{|c|c|c|c|c|}
\hline Section ID & Peak hour volume (PCU) " $V$ " & Capacity (PCU) “C” & $V / C$ & Type of the carriageway \\
\hline UR01 & 1635 & 1800 & 0.90 & 4-Lane undivided (two-way) \\
\hline UR02 & 611 & 2900 & 0.21 & 4-Lane divided (two-way) \\
\hline UR03 & 845 & 3200 & 0.26 & 2-Lane (two-way) \\
\hline UR04 & 750 & 2200 & 0.34 & 4-Lane divided (two-way \\
\hline UR05 & 1355 & 2900 & 0.46 & 4-Lane divided (two-way) \\
\hline UR06 & 1433 & 1800 & 0.80 & Undivided 4-Lane (two-way) \\
\hline UR07 & 2622 & 2900 & 0.90 & 4-Lane divided (two way) \\
\hline UR08 & 1934 & 2900 & 0.67 & 4-Lane divided (two-way) \\
\hline UR09 & 680 & 900 & 0.75 & 2-Lane (two-way) \\
\hline UR10 & 1156 & 900 & 1.28 & 2-Lane (divided) two-way \\
\hline UR11 & 1992 & 4300 & .46 & 6-Lane divided (two-way) \\
\hline UR12 & 1485 & 1200 & 1.2 & 6-Lane divided (two-way) \\
\hline UR13 & 2244 & 2200 & 1.02 & 4-Lane divided (two-way) \\
\hline UR14 & 1936 & 2900 & 0.66 & 6-Lane divided (two-way) \\
\hline UR15 & 2932 & 2900 & 0.10 & 4-Lane divided (two-way) \\
\hline UR16 & 529 & 1800 & 0.29 & 4-Lane undivided \\
\hline
\end{tabular}

deviation for all the corrected rebound deflection values for a particular section. From the BBD values determined as above, the modified structural number (MSN) for all the pavement sections has been calculated [30]:

$$
\mathrm{MSN}=3.2 \times D^{-0.63} .
$$

Figure 2 shows the BBD survey on UR02, and Figure 3 presents the progressive variations of $\mathrm{BBD}$ observed during 


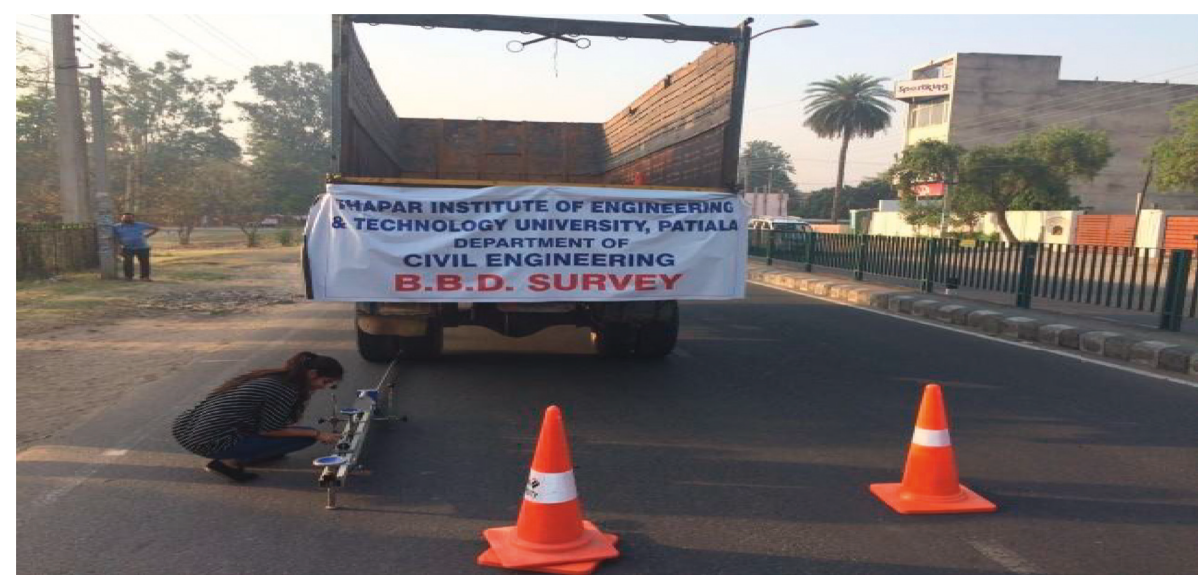

FIGURE 2: BBD test in progress at chainage $0.350 \mathrm{~km}$ on the section UR02.

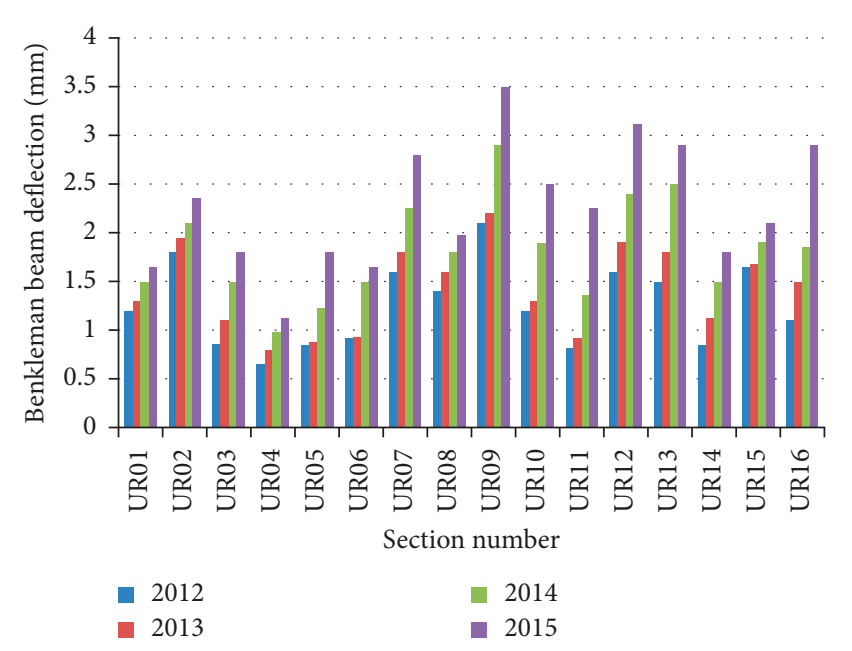

FIgURE 3: Measured BBD for the road sections UR01 to UR16.

the years 2012-2015 on the selected road sections of Patiala City, that is, UR01 to UR16.

2.4. Functional Evaluation of Pavements. Functional evaluation of pavements consists of collection of road condition data related to surface distress including pavement distress in terms of cracks, potholes, rutting, and ravelling. In the present study, cracking, potholes, ravelling, rutting, and roughness have been measured for all the selected road sections for the development of prediction models for pavement distress. The two other parameters, skid resistance and mean texture depth, have been also measured. Skid resistance has been measured in terms of skid resistance value and sideways force coefficient (SFC). But, there has not been any noticeable decrement in the value of SFC from the year 2012 to 2015. Similarly, there has not been any significant change in the mean texture depth measured using the "Sand Patch Method."

2.4.1. Cracking Measurement. A number of representative test sections of length $100 \mathrm{~m}$ have been selected for cracking measurements for each pavement section. Cracking (alligator, longitudinal, and transverse) has been visually inspected. In case of alligator cracking, the area covered under the distress has been marked in the form of a rectangular box with a chalk on the ground and is measured with a tape. In case of longitudinal and transverse cracks, effective width has been taken as $50 \mathrm{~cm}$ and actual length has been measured. Cracked area is expressed as the percentage of the total pavement area. Figure 4 shows the cracks present on the road section UR09, and Figure 5 shows the progressive variation of the cracking area for the road sections UR01 to UR16 during the years 2012-2015.

2.4.2. Pothole Measurement. Pothole means open cavity on the pavement. Measurement of potholes for each road section has been done visually. Minimum diameter of $150 \mathrm{~mm}$ and minimum depth of $25 \mathrm{~mm}$ of pothole have been taken [28]. Figure 6 shows the pothole on the section UR04, and Figure 7 shows the progressive variations of potholes for the road sections UR01 to UR16 during the years 2012-2015.

2.4.3. Ravelling Measurement. Ravelling is the loss of material from wearing surface. This distress type is associated with thin surfacing, such as, surface dressing, seal coat, and premix carpet. The affected area has been measured by taking into account the area enclosed in regular geometric shapes, and then it has been expressed as the percentage of the total pavement area. Figure 8 shows the ravelling on the section UR13, and Figure 9 shows the progressive variations of ravelling for the road sections UR01 to UR16 during the years 2012-2015.

2.4.4. Rutting Measurement. Rutting refers to permanent deformation on the pavement surface in the wheel path. Permanent deformation is commonly defined as distortions within the individual layers of the pavement structure. Rutting is caused by structural and/or material failure that can lead to hazardous driving conditions. It is very common in flexible pavements. The rut depth has been measured with 


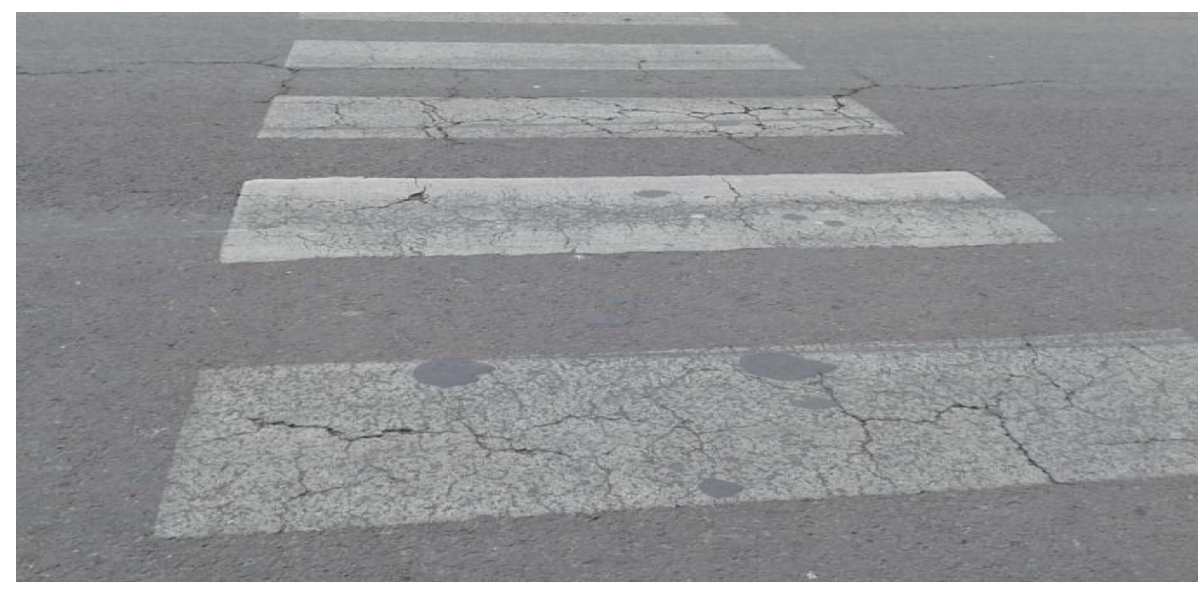

FIGURE 4: Cracks on the road section UR09.

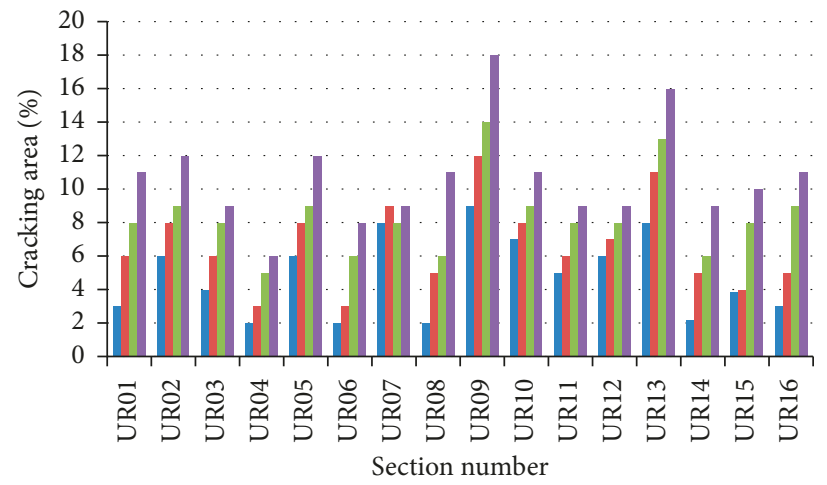
- 2012
- 2014
- 2013
- 2015

FIgURE 5: Progressive variation of the cracking area for the road sections UR01 to UR16.

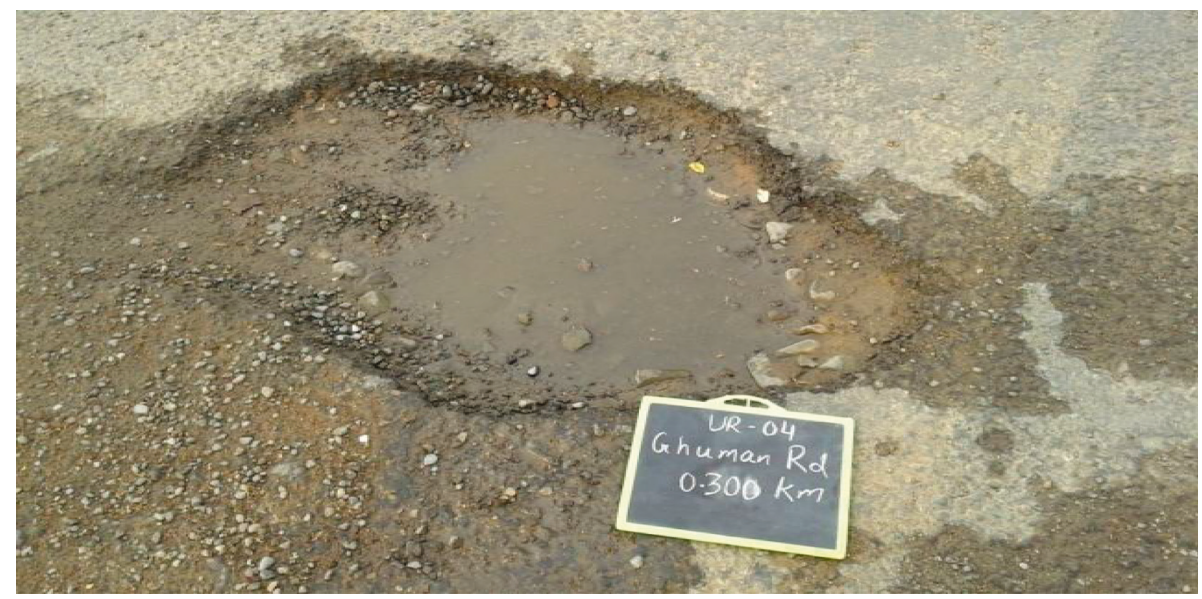

FIgURE 6: Pothole at chainage $0.300 \mathrm{~km}$ on the section UR04.

$2 \mathrm{~m}$ straight edge placed in the transverse direction. Twelve observations have been carried out for each selected road section. The maximum rut depth (in $\mathrm{mm}$ ) has been taken in each observation slot. The rut depths have been averaged to get the mean rut depth of the selected road section. Figure 10 shows the rutting on the section UR01, and Figure 11 shows the progressive variation of rutting for the road sections UR01 to UR16 during the years 2012-2015.

2.4.5. Roughness Measurement. Road roughness refers to surface irregularities in the longitudinal direction. Roughness is 


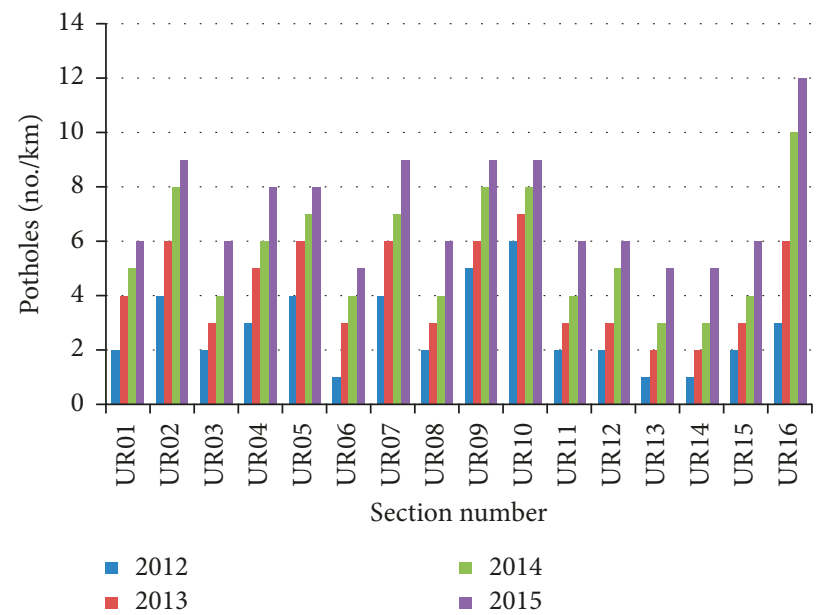

FIgURE 7: Progressive variation of potholes for the road sections UR01 to UR16.

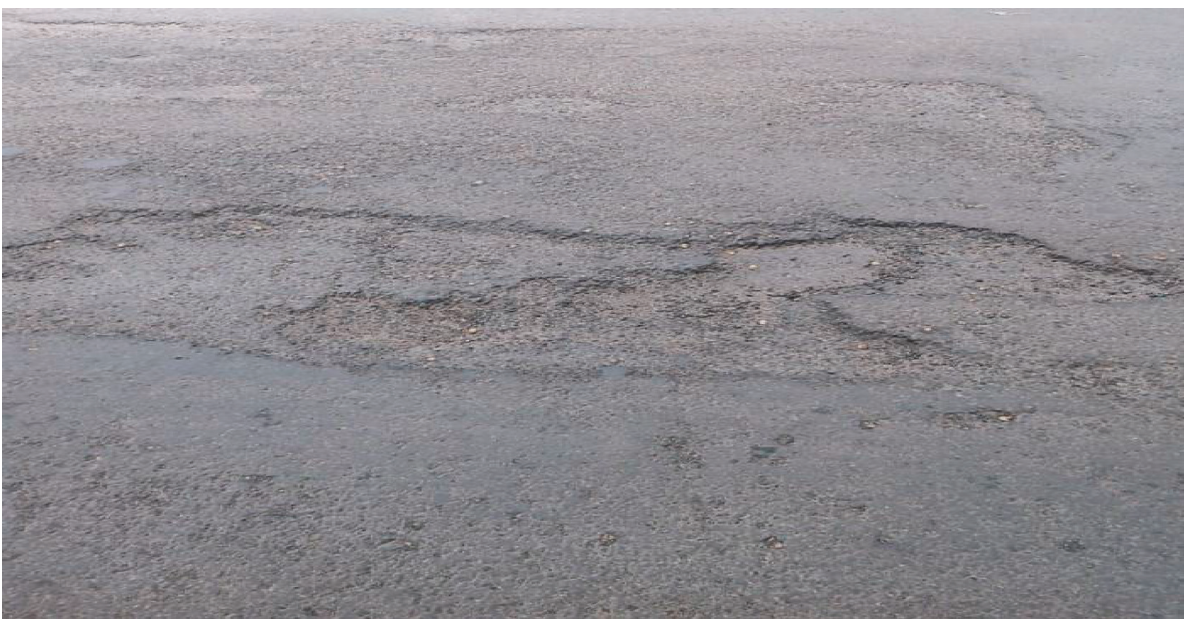

FIGURE 8: Ravelling at chainage $0.300 \mathrm{~km}$ on the section UR13.

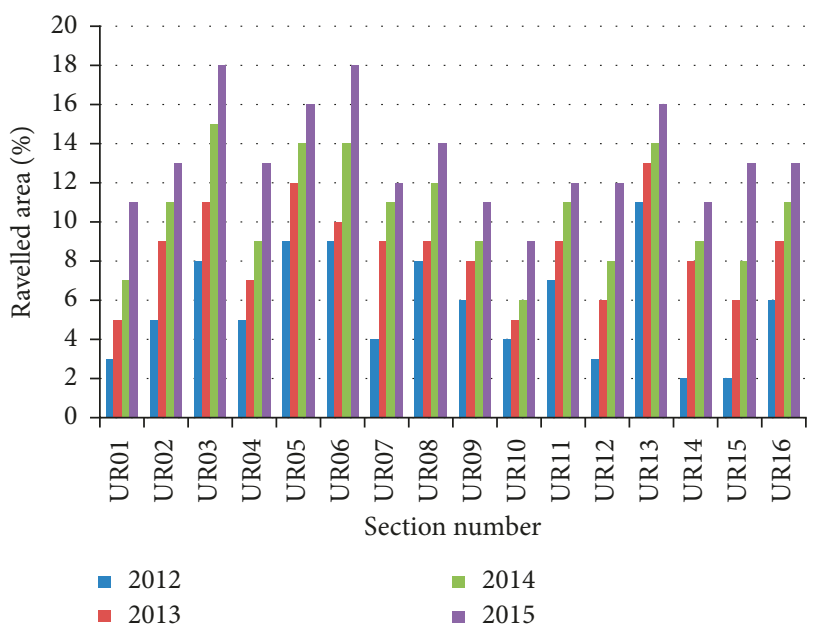

Figure 9: Progressive variation of ravelling for the road sections UR01 to UR16. an important pavement evaluation parameter because it affects not only ride quality but also vehicle delay costs, fuel consumption, and maintenance costs. Roughness has been measured with the fifth wheel bump integrator or simply known as roughometer. Unevenness Index (in $\mathrm{cm} / \mathrm{km}$ ) has been calculated for each section with the following equation:

$$
\begin{aligned}
\text { Unevenness Index (UI) }= & \text { bumps in } \mathrm{cm} / \\
& \text { length travelled in } \mathrm{km} .
\end{aligned}
$$

Roughness has been calculated in the form of International Roughness Index (IRI, m/km). Above Unevenness Index (UI) value has been converted into International Roughness Index (IRI in $\mathrm{m} / \mathrm{km}$ ) by using the following equation [28]:

$$
\mathrm{IRI}=\left(\frac{1}{630} \times \mathrm{UI}\right)^{1 / 1.12}
$$

where UI is the Unevenness Index in $\mathrm{mm} / \mathrm{km}$. IRI is the International Roughness Index in $\mathrm{m} / \mathrm{km}$. Figure 12 shows bump integrator test (roughness test) in progress on the section UR11, and Figure 13 shows the progressive variations 


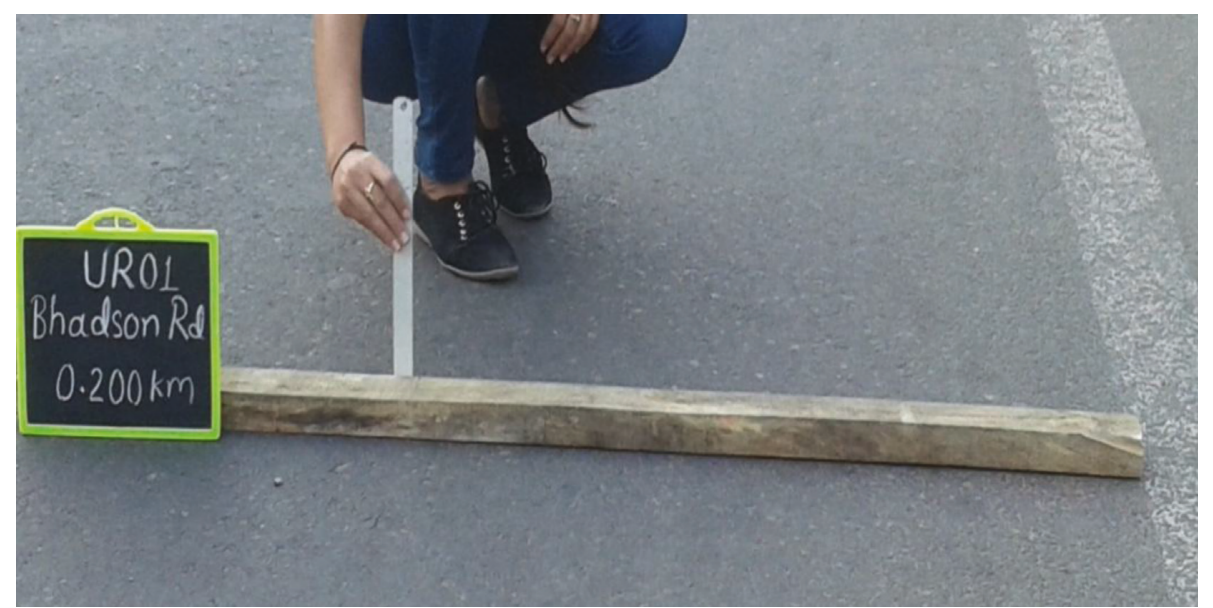

FIgURE 10: Rut depth measurement at chainage $0.200 \mathrm{~km}$ on the section UR01.

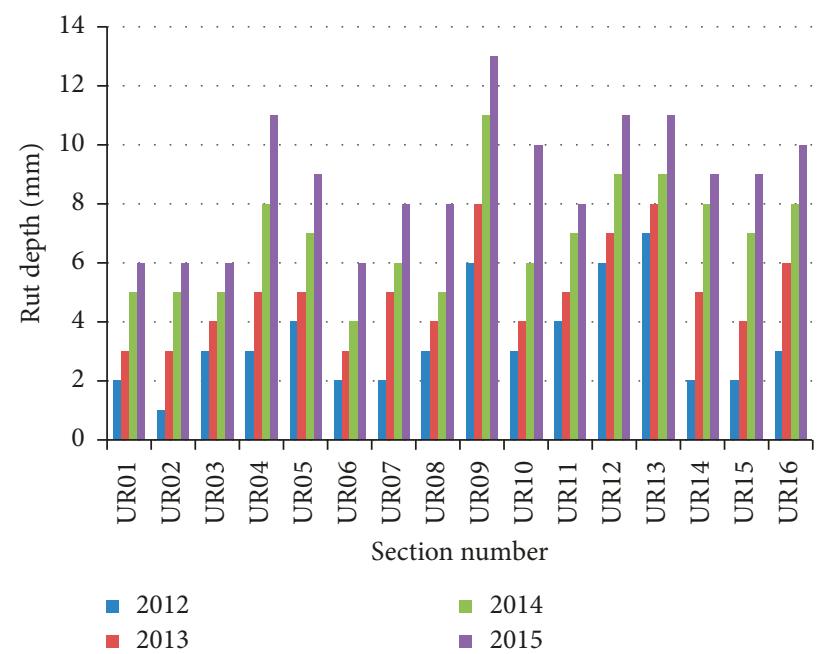

FIgURE 11: Progressive variation of rutting for the road sections UR01 to UR16.

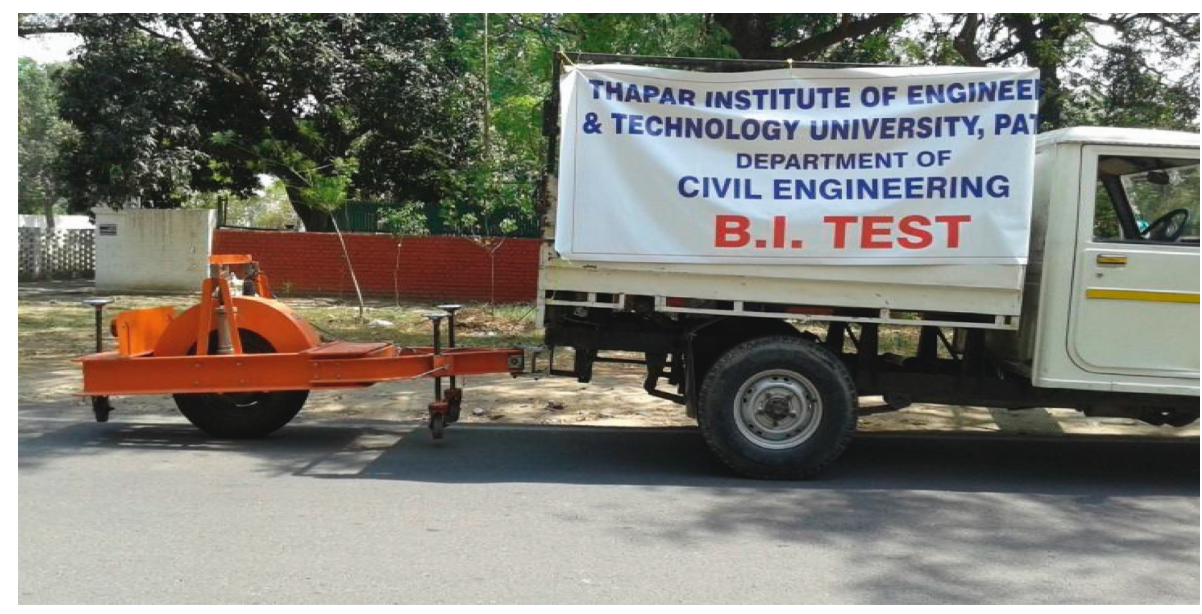

FIGURE 12: Bump integrator test (roughness test) in progress on the section UR11. 


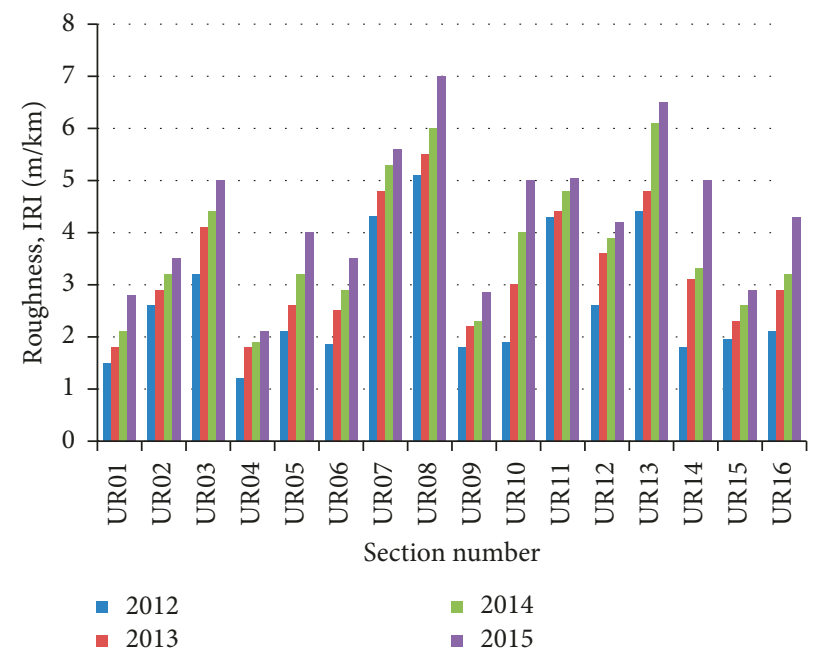

FIgURe 13: Progressive variation of IRI for the road sections UR01 to UR16.

TABle 4: Architecture of the GP model.

\begin{tabular}{lcc}
\hline Parameters & Values & Description \\
\hline Initial population size & Dataset & $\begin{array}{c}\text { Dataset-1 is of } 16 \text { instances consisting of data } \\
\text { gathered in } 2012 \text { and } 2013 .\end{array}$ \\
Function set & $+,-, *, l, \operatorname{sqrt}(), \tanh (), \operatorname{pow}(\mathrm{x}, \mathrm{y})$, & Set of functions used \\
Training percentage & 70 & - \\
Selection method & Tournament ()$, \exp (), \operatorname{pow}(\mathrm{x}, 2)$, fabs () & - \\
Tournament size of replacement & 3 & Maximum number of iterations \\
Maximum generations & 100000 & Probability of crossover \\
Crossover & 0.8 & Probability of mutation \\
Mutation & 0.04 & Population size \\
$\mu$ & 200 & Number of children produced \\
$\lambda$ & 250 & Coefficient of determination \\
Fitness functions & $R^{2}$ & Root mean square error \\
\hline
\end{tabular}

of IRI for the road sections UR01 to UR16 during the years 2012-2015.

\section{Methods}

GP has commenced as an endeavor to discover how computers could be trained to solve problems without being explicitly programmed to do so. GP is an extension of genetic algorithms proposed by Koza [29] who defines GP as a domain independent problem solving impends in which computer programs are evolved to solve, or approximately solve, problems based on Darwinian principles of reproduction and analogs of naturally occurring genetic operations such as reproduction, crossover, and mutation. The five major prelude steps for the basic version of GP require the user to specify (a) the set of terminals for each stem of the to-be-evolved program; (b) the set of primitive functions for each stem of the to-be-evolved program; (c) the fitness measure; (d) certain parameters for controlling the run; and (e) the termination criterion and method for designating the result of the run.
3.1. Steps to Execute GP. The execution steps of GP are as follows:

(1) Select the dataset that has to be used as initial population (generation 0 ) with the available functions and terminals.

(2) Apply the following steps iteratively on the population until the termination criterion has been satisfied:

(a) Execute each program in the population and ascertain its fitness (explicitly or implicitly) using the problem's fitness measure.

(b) Select one or two individual(s) from the population based on the probability of fitness measure to participate in the genetic operations in (c).

(c) Generate new individual(s) for the population with the help of following genetic operations:

(i) Reproduction: copy the selected individual to the new population.

(ii) Crossover: create new children for the new population by recombining randomly chosen parts from two selected individuals. 
TABLE 5: GP models for progression of cracking, potholes, ravelling, rutting, and roughness for urban roads.

\begin{tabular}{|c|c|}
\hline & Values \\
\hline $\begin{array}{l}\text { Model } 1 \\
\text { (cracking } \\
\text { progression) }\end{array}$ & $\begin{array}{l}\qquad \mathrm{CA}_{j}=\left(1 / \mathrm{MSN}_{i}\right)\left(\left(\mathrm{MSN}_{i} \times \mathrm{CA}_{i}\right)+\left(\left(e^{\left(\left(\mathrm{CA}_{i} \times e^{-\mathrm{ESA}_{i}}\right) /\left(\mathrm{AGE}_{\mathrm{i}}\right)\right)}\right) / \mathrm{AGE}_{i}\right)+\left(\left(2 \mathrm{MSN}_{i}+\mathrm{AGE}_{i}+e^{\left.\left.\left.\mathrm{ESA}_{i}\right) / \mathrm{CA}_{i}\right)+1\right) \text {, }}\right.\right.\right. \\
\text { where } \mathrm{CA}_{j} \text { is the cracking of the next year, } \mathrm{CA}_{i} \text { is the cracking of the previous year, } \mathrm{MSN}_{i} \text { is the modified structural number } \\
\text { of the previous year, } \mathrm{AGE}_{i} \text { is the age of the pavement before the start of the analysis year, and } \mathrm{ESA}_{i} \text { is the number of } \\
\text { equivalent standard axle repetitions in the analysis year (in millions) }\end{array}$ \\
\hline $\begin{array}{l}\text { Model } 2 \\
\text { (ravelling } \\
\text { progression) }\end{array}$ & $\begin{array}{l}\mathrm{RA}_{j}=1+\mathrm{RA}_{i}+\left(\left(\mathrm{AGE}_{i}\left(1+\mathrm{ESA}_{i}\right)+2\left(\mathrm{RA}_{i}+e^{\sqrt{\mathrm{AGE}_{i}}}\right)\right) /\left(\mathrm{RA}_{i}\left(\mathrm{ESA}_{i}+\mathrm{AGE}_{i}\right)\right)\right)+\tanh \left(\mathrm{AGE}_{i}^{2}\left(\left(\mathrm{AGE}_{i} \times \mathrm{ESA}_{i}\right)-\mathrm{RA}_{i}\right)\right) \text {, } \\
\text { where } \mathrm{RA}_{j} \text { is the ravelling area of the next year and } \mathrm{RA}_{i} \text { is the ravelling of the previous year, } \mathrm{AGE} \mathrm{i}_{i} \text { is the age of the pavement before } \\
\text { the start of the analysis year, and } \mathrm{ESA}_{i} \text { is the number of equivalent standard axle repetition in the analysis year (in millions) }\end{array}$ \\
\hline $\begin{array}{l}\text { Model } 3 \\
\text { (potholes } \\
\text { progression) }\end{array}$ & $\begin{array}{l}\qquad \mathrm{POT}_{j}=\tanh \left(e^{\tanh \left(\mathrm{CA}_{i}\right)}+\mathrm{RA}_{i}+\mathrm{POT}_{i}\right)+\mathrm{POT}_{i}-\mathrm{ESA}_{i}-\tanh \left(\mathrm{POT}_{i}-\tanh \left(\mathrm{POT}_{i}-\tanh \left(\sqrt{\tanh \left(\mathrm{AGE}_{i}\right)}\right)-\mathrm{AGE}_{i}\right)\right) \text {, } \\
\text { where } \mathrm{POT}_{j} \text { is the pothole of the next year (number per km), } \mathrm{POT}_{i} \text { is the pothole of the next year (number per km), CA }{ }_{i} \text { is } \\
\text { the cracking of the previous year, } \mathrm{RA}_{i} \text { is the ravelling area of the previous year, } \mathrm{AGE}_{i} \text { is the age of the pavement before the } \\
\text { start of the analysis year, and } \mathrm{ESA}_{i} \text { is the number of equivalent standard axle repetition in the analysis year (in millions) }\end{array}$ \\
\hline $\begin{array}{l}\text { Model } 4 \\
\text { (rutting } \\
\text { progression) }\end{array}$ & $\begin{array}{l}\qquad \mathrm{RD}_{j}=\mathrm{RD}_{i}+\mathrm{DF}+\tanh \left(\mathrm{RD}_{i}(\mathrm{MSN}-\mathrm{DF}-1) /\left(\log \left(\mathrm{MSN} / \mathrm{ESA}_{i}\right)+\mathrm{CA}_{i}+\mathrm{AGE}_{i}+\left(\mathrm{RD}_{i} / 2 \mathrm{MSN}+\log (\mathrm{MSN})\right)\right)\right) \text {, } \\
\text { where } \mathrm{RD}_{j} \text { is the rutting of the next year, } \mathrm{RD}_{i} \text { is the rutting of the previous year, } \mathrm{MSN}_{i} \text { is the modified structural number of the } \\
\text { previous year, } \mathrm{AGE}_{i} \text { is the age of the pavement before the start of the analysis year, } \mathrm{DF} \text { is the drainage factor, } \mathrm{CA}_{i} \text { is the cracking } \\
\text { of the previous year, and } \mathrm{ESA}_{i} \text { is the number of equivalent standard axle repetitions in the analysis period (in millions) }\end{array}$ \\
\hline $\begin{array}{l}\text { Model } 5 \\
\text { (roughness } \\
\text { progression) }\end{array}$ & $\begin{array}{l}\qquad \mathrm{IRI}_{j}=1.254\left(\left(\left(\mathrm{ESA}_{i} \times \mathrm{AGE}_{i} \times \mathrm{IRI}_{i}\right) /\left(\left(\mathrm{ESA}_{i} \times \mathrm{RD}_{i} \times d \mathrm{NPT} \times \mathrm{AGE}_{i}\right)+\left(12.048 \times \mathrm{IRI}_{i}\right)+\left(\mathrm{ESA}_{i}^{3} \times \mathrm{AGE}_{i}\right)\right)\right)\right. \\
+\left(\mathrm{IRI}_{i}\right) \sqrt{\left.\mathrm{ESA}_{i}\right),}\end{array}$ \\
\hline
\end{tabular}

TABLE 6: Results of the proposed models for training dataset.

\begin{tabular}{lccc}
\hline Dataset & Model & $R^{2}$ & RMSE \\
\hline & Model 1 & 0.96 & 0.48 \\
& Model 2 & 0.84 & 0.53 \\
Training dataset (2013) & Model 3 & 0.90 & 0.93 \\
& Model 4 & 0.97 & 0.27 \\
& Model 5 & 0.79 & 0.04 \\
\hline
\end{tabular}

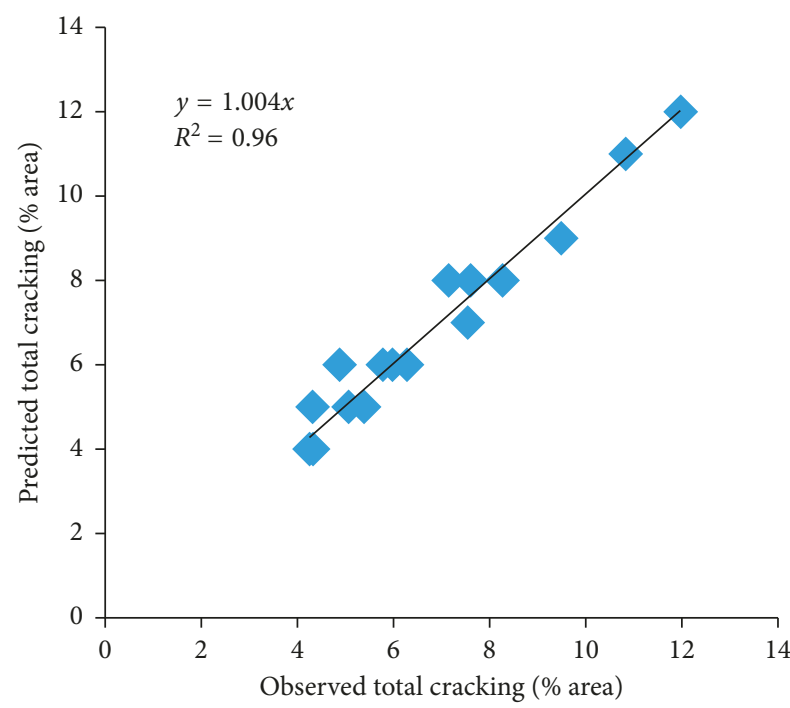

Figure 14: Scatter plot between observed versus predicted total cracking for training.

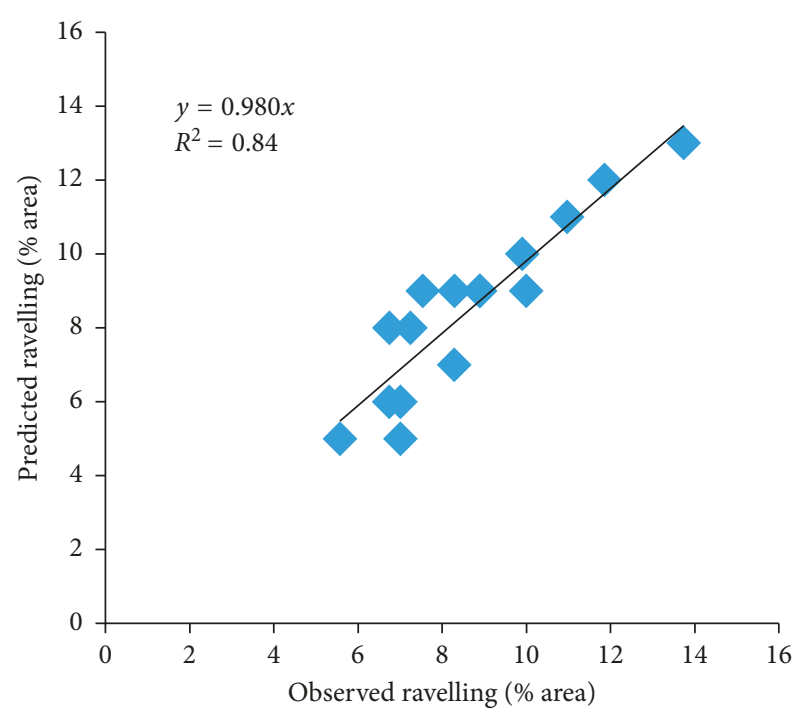

FIGURE 15: Scatter plot between observed versus predicted ravelling for training.

(iii) Mutation: create one new child for the new population by randomly mutating a randomly chosen part of one selected individual.

(iv) Architecture-altering operations: choose operation from the available repertoire of such operations and create one new child for the new population by applying the selected architecture-altering operation to one selected individual. 


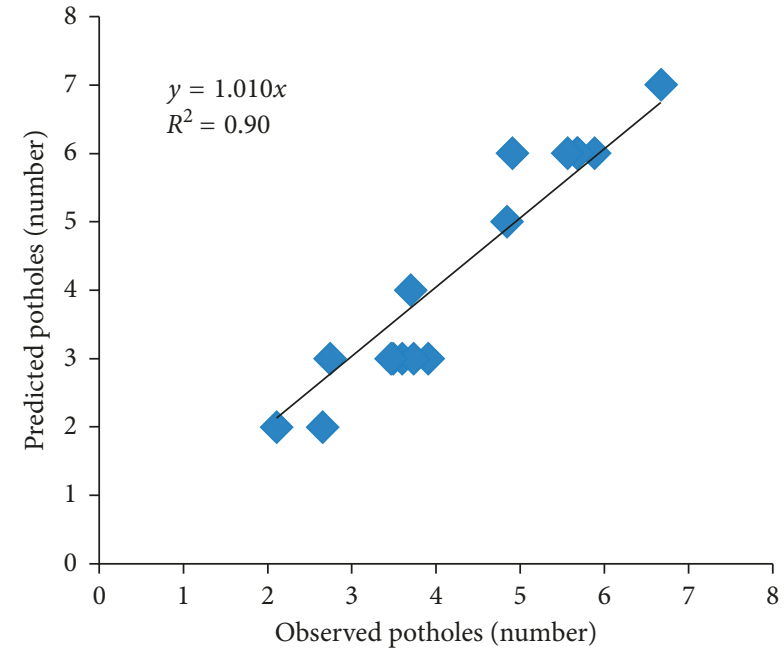

FIGURE 16: Scatter plot between observed versus predicted potholes for training.

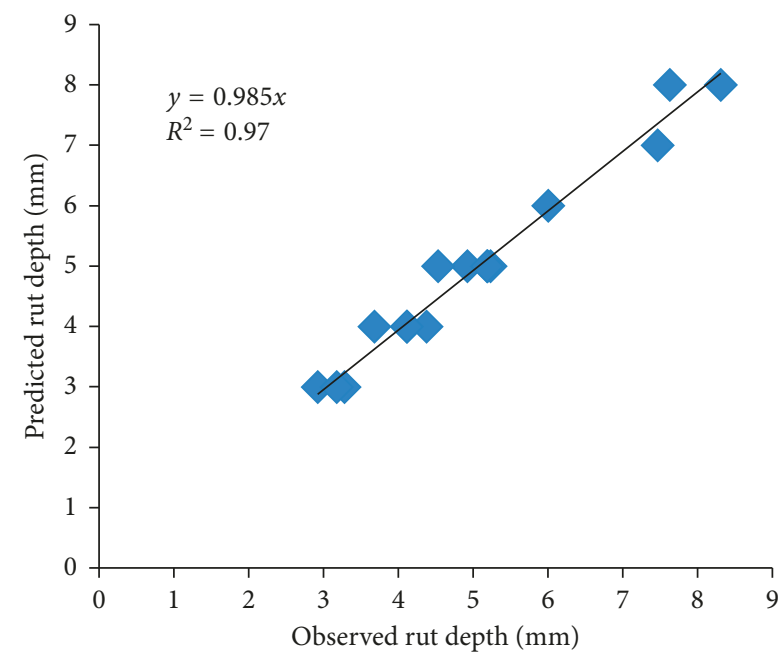

FIGURE 17: Scatter plot between observed versus predicted rutting for training.

(3) When termination criterion has been satisfied, the best program in the population produced during the run has been designated as the result of the experiment. If the experiment is successful, the result may be a solution (or approximate solution) to the problem.

3.2. Development of the GP Model. The control parameters as given in Koza [29] have been investigated in this study. The population size $(\mu)$ and the number of children produced $(\lambda)$ have been taken as 200 and 250, respectively. The larger is the number of generations, the greater are the chances of evolving a solution; hence, the number of generations has been taken as 100000 . The values for the parameters, namely, crossover rate and mutation rate, have been selected as 0.80 and 0.04 , respectively, after experimentations. The values of other parameters, that is, training

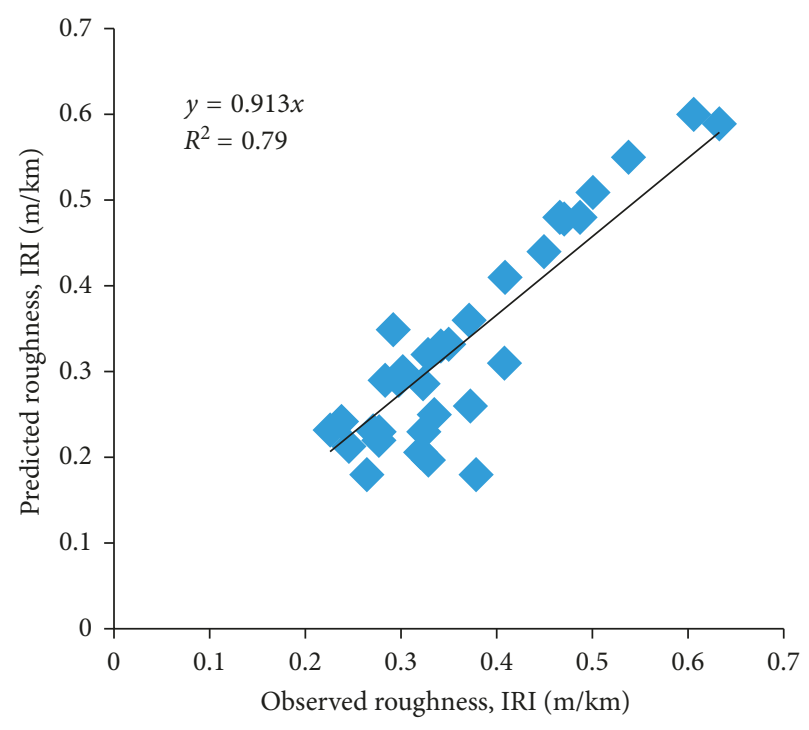

FIGURE 18: Scatter plot between observed versus predicted roughness for training.

TABle 7: Results of the proposed models for validation dataset.

\begin{tabular}{lccc}
\hline Dataset & Model & $R^{2}$ & RMSE \\
\hline & Model 1 & 0.77 & 0.60 \\
Validation dataset (2014) & Model 2 & 0.78 & 0.62 \\
& Model 3 & 0.84 & 0.71 \\
& Model 4 & 0.80 & 0.86 \\
& Model 5 & 0.81 & 0.76 \\
& Model 1 & 0.75 & 0.89 \\
& Model 2 & 0.75 & 0.90 \\
Validation dataset (2015) & Model 3 & 0.90 & 0.70 \\
& Model 4 & 0.81 & 0.90 \\
& Model 5 & 0.73 & 0.09 \\
\hline
\end{tabular}

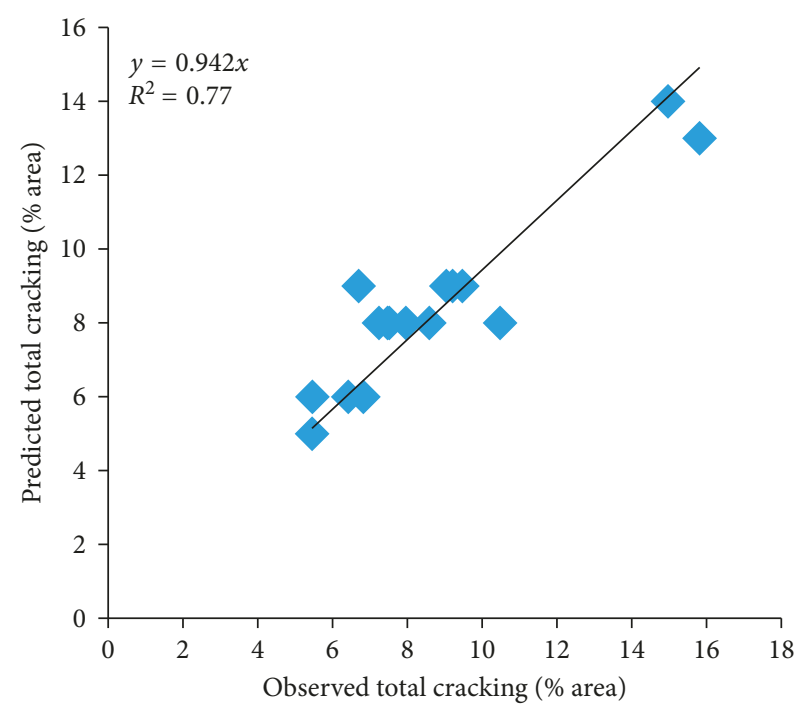

FIGURE 19: Scatter plot between observed versus predicted total cracking for validation (2014). 


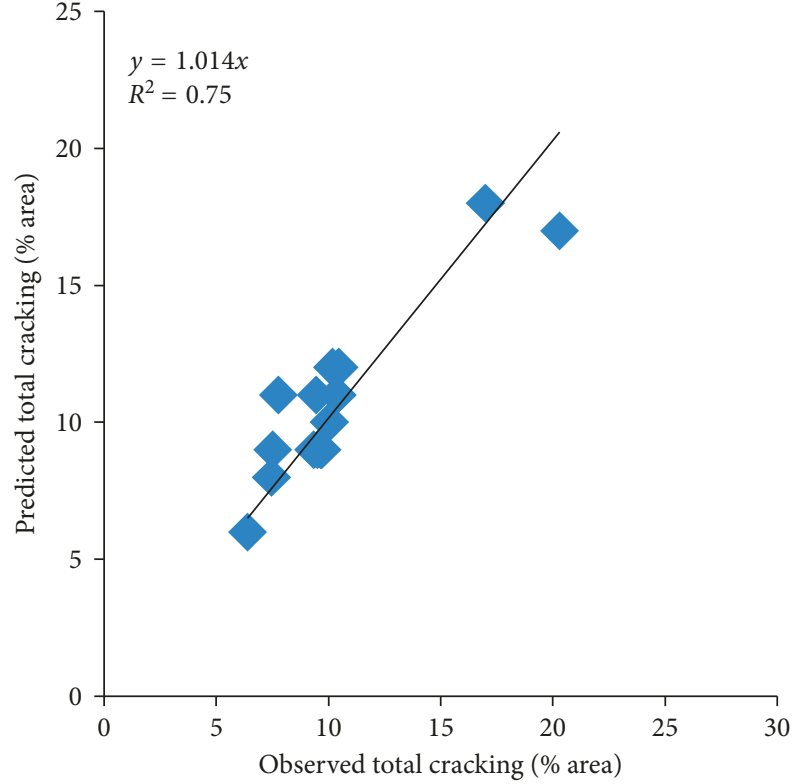

Figure 20: Scatter plot between observed versus predicted total cracking for validation (2015).

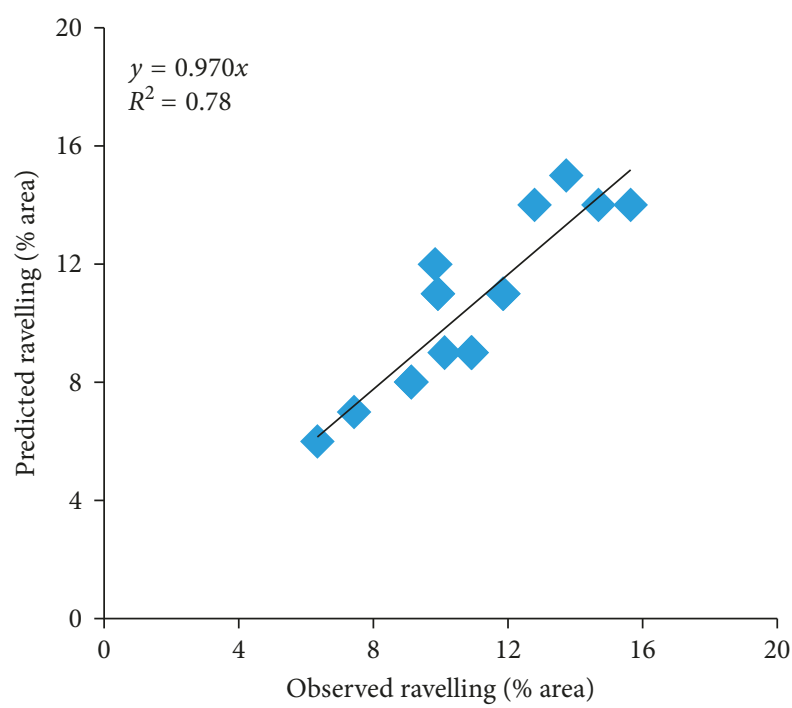

FIGURE 21: Scatter plot between observed versus predicted ravelling for validation (2014).

percentage, selection method, and tournament size of substitution, are taken as 70, "tournament" and 3, respectively, for the development of the GP model. Function set $(+,-, *, /, \operatorname{sqrt}(), \tanh (), \exp (), \log (), \operatorname{fabs}(), \operatorname{pow}(\mathrm{x}, \mathrm{y})$, $\operatorname{pow}(\mathrm{x}, 2))$ has been taken for generation of model equations. The architectural details of the selected GP model are given in Table 4.

3.2.1. Models Generated Using GP. In the GP model development, the addition is chosen as the linking utility. The prediction models generated using the GP are listed in Table 5. It consists of five models: Model 1, Model 2, Model

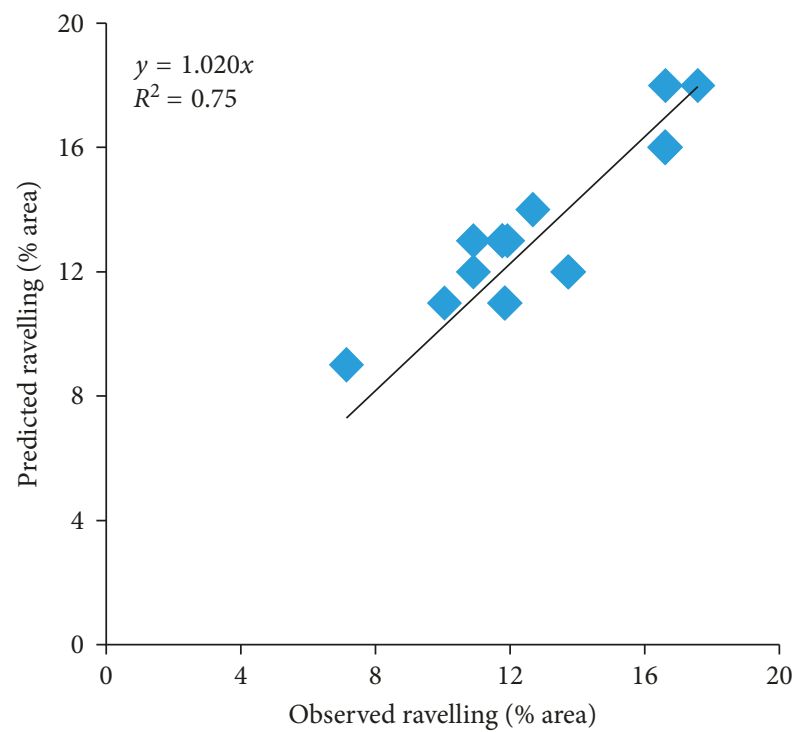

FIGURE 22: Scatter plot between observed versus predicted ravelling for validation (2015).

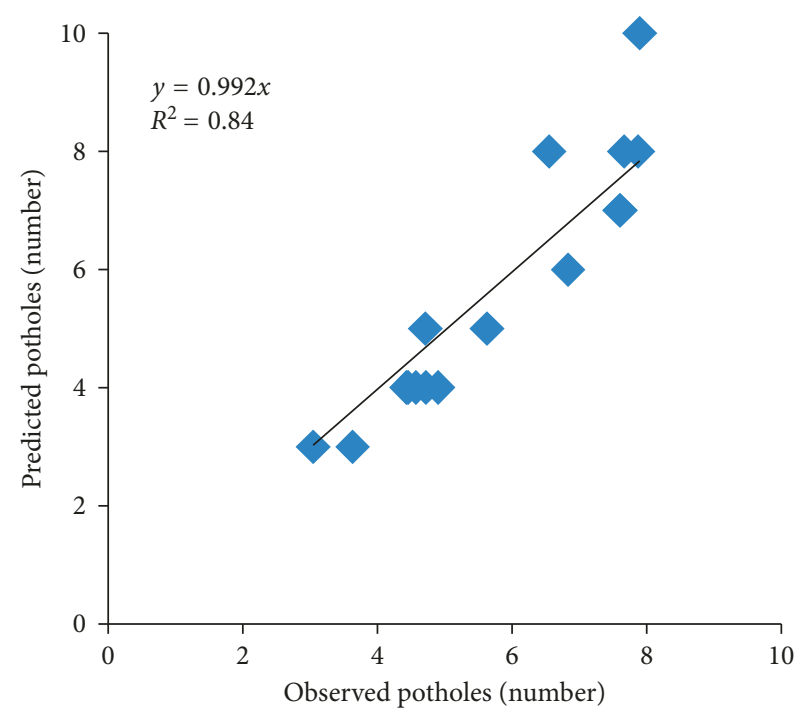

FIGURE 23: Scatter plot between observed versus predicted potholes for validation (2014).

3, Model 4, and Model 5 for cracking, ravelling, potholes, rutting, and roughness, respectively.

\section{Results and Discussions}

The results obtained from this approach have been used for the quantitative assessment of the model's predictive abilities and are presented in Table 6. The dataset gathered during the years 2012 and 2013 has been used for training models; that is, for the prediction of the year 2013 pavement distress, the dataset of the year 2012 has been used. The postregression fits for the training dataset of all the models (Model 1, Model 2, Model 3, Model 4, and Model 5) are presented in Figures 14-18, respectively. It can be observed 


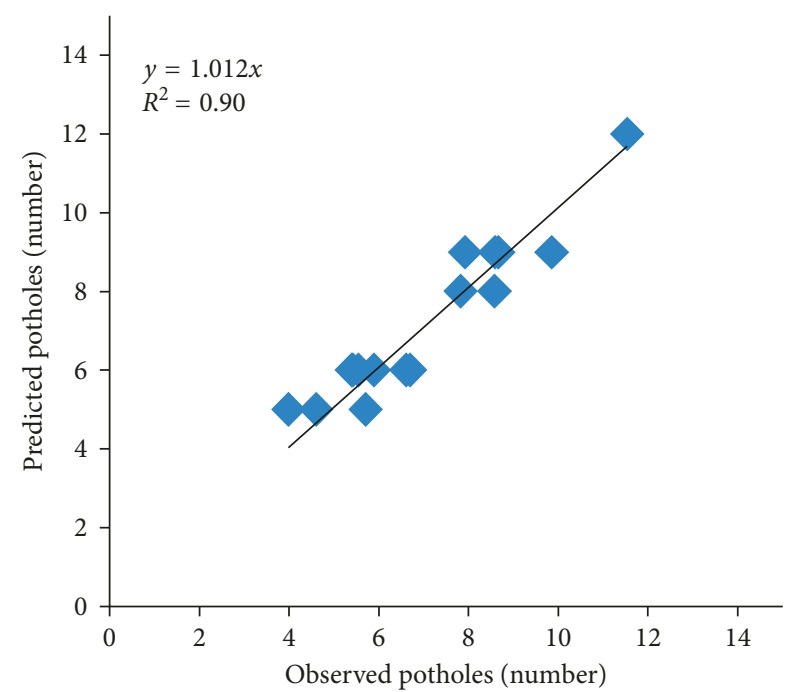

Figure 24: Scatter plot between observed versus predicted potholes for validation (2015).

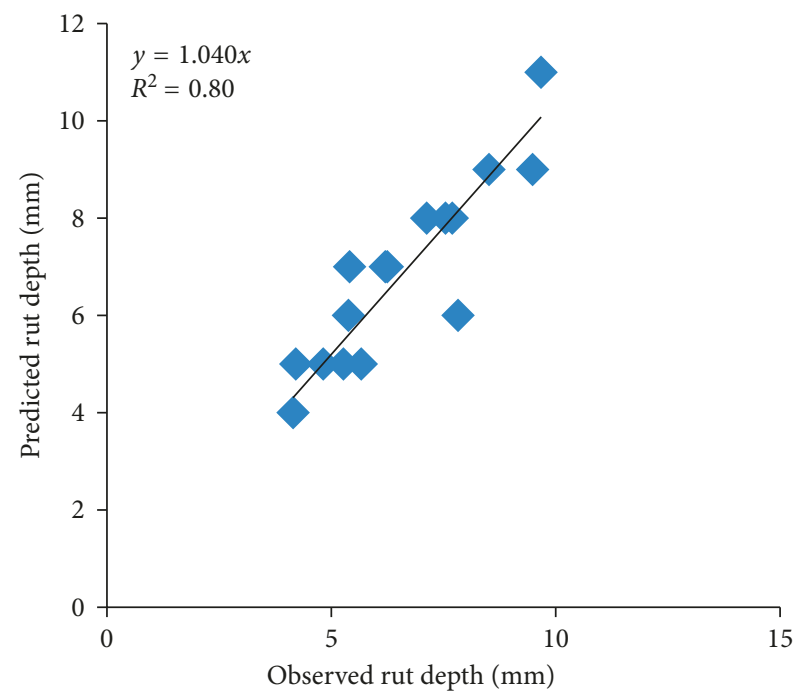

FIGURE 25: Scatter plot between observed versus predicted rutting for validation (2014).

from Figures 14-18 that the some deviation can be noticed between the observed and predicted values because of the modeling approach adopted and because of the assumed normal construction quality for the bituminous surfacing considering the use of optimum binder content in bituminous base and wearing courses as per the routine practice for maintaining the urban roads in India. But, this deviation is quite reasonable for the urban road sections of different age and traffic loading conditions.

4.1. Validation of GP Models. To further test the efficacy and reliability of the models, the datasets collected during the years 2014 and 2015 have been used for the validation purposes. The results of proposed models for validation dataset of year 2014 and year 2015 are presented in Table 7. For the prediction of

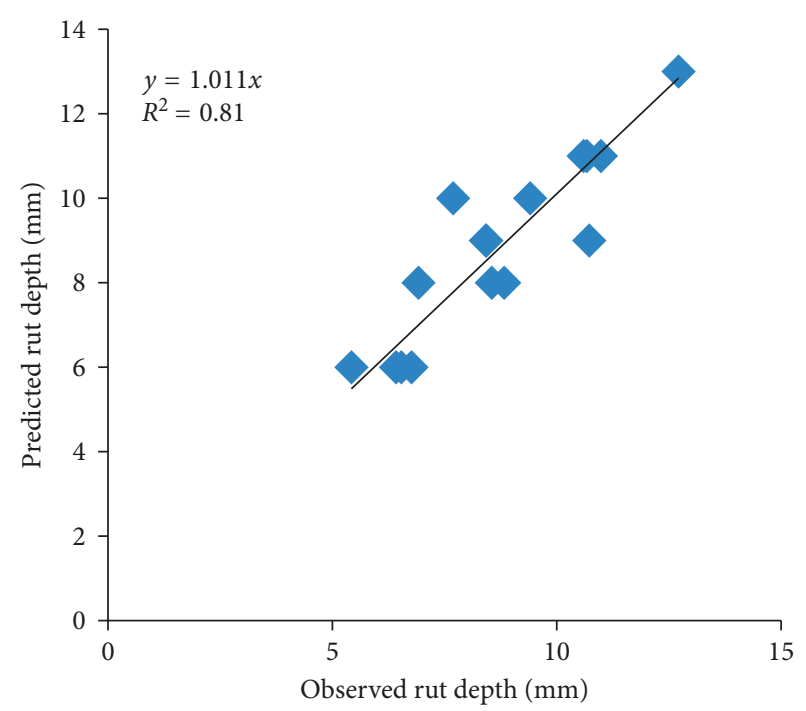

FIGURE 26: Scatter plot between observed versus predicted rutting for validation (2015).

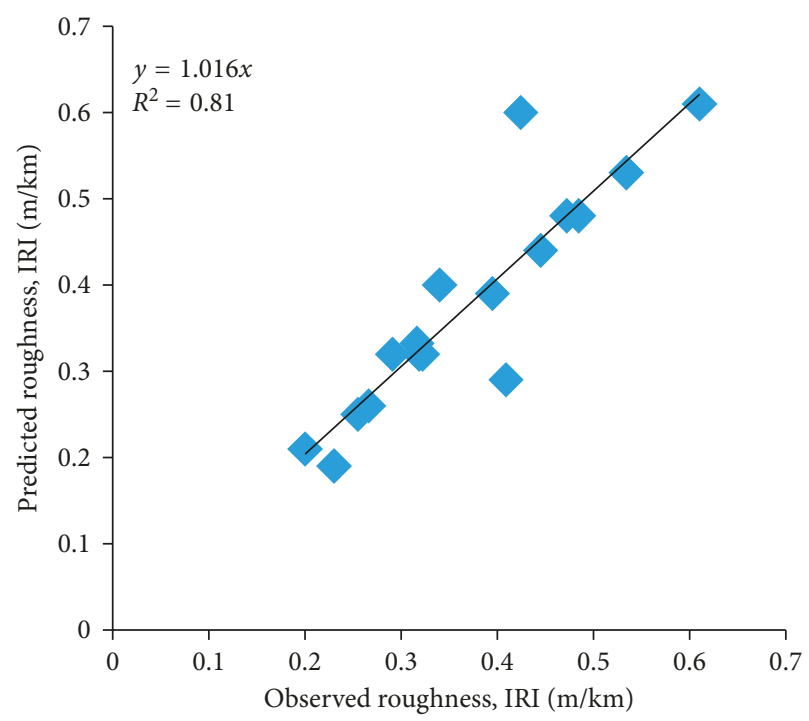

FIGURE 27: Scatter plot between observed versus predicted roughness for validation $\left(0.1^{*}\right.$ IRI in 2014).

pavement distress of the year 2014, the data gathered during the year 2013 has been used, and for the prediction of pavement distress of year 2015, the data gathered during the year 2014 has been used. The postregression fits for the validation datasets (2014-2015) of all the models (Model 1, Model 2, Model 3, Model 4, and Model 5) are presented in Figures 19-28, respectively. All the GP models have been predicting with good competence for both the datasets (2014 and 2015). The results are revealing that these GP models can be applied successfully to the roads of Patiala City, Punjab, India.

\section{Conclusions}

(i) The objective of this study was to explore the applicability of GP models for pavement distress. Five 


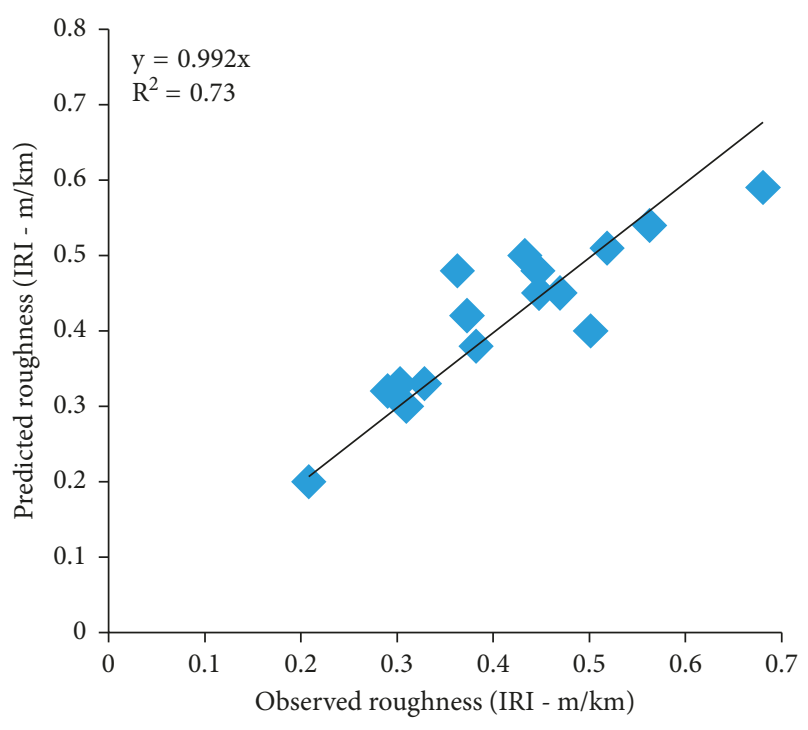

Figure 28: Scatter plot between observed versus predicted roughness for validation $\left(0.1^{*}\right.$ IRI in 2015$)$.

models have been developed for the cracking progression (Model 1), ravelling progression (Model 2), pothole progression (Model 3), rutting progression (Model 4), and roughness progression (Model 5). The data collected during the year 2012 to year 2015 on the 16 selected roads of Patiala, Punjab, India, have been used for the development of these models.

(ii) We can say that GP has built a good correlation between observed and predicted values and the parameters (like cracking, ravelling, pothole, rutting, and roughness) that have been taken in the present study are sufficient for the prediction of pavement distress.

(iii) The deviations between observed and predicted values are only because of the modeling approach adopted and because of the assumed normal construction quality for the bituminous surfacing considering the use of optimum binder content in bituminous base and wearing courses, but this deviation is quite reasonable for the urban road sections of different age and traffic loading conditions.

(iv) These models can be applied to other city roads with a range of traffic varying from 0.1 to 0.85 equivalent standard axle repetitions in the initial analysis year and MSN in the range of 2 to 4.5 .

(v) As an outcome, we can say that GP models provide good results for the prediction of pavement distress and may serve as a predictive model for the prediction of pavement distress for all the cities having homogeneous traffic and climate conditions like Patiala, Punjab, India.

\section{Conflicts of Interest}

The authors declare that there are no conflicts of interest regarding the publication of this paper.

\section{References}

[1] MoRTH, Road Transport Year Book 2010/2011, Transport Research Wing, Ministry of Road Transport and Highways, Government of India, New Delhi, India, 2012.

[2] OECD, Pavement Management Systems, Road Transport Research Group, Organization for Economic Cooperation and Development, OECD, Paris, France, 1987.

[3] CRRI, Master Plan for Improvement of Roads in Delhi, Pavement Evaluation Division, Central Road Research Institute, New Delhi, India, 1993.

[4] M. M. Aydin and A. Topal, "Effect of road surface deformations on lateral lane utilization and longitudinal driving behaviours," Transport, vol. 31, no. 2, pp. 192-201, 2016.

[5] J. Ben-Edigbe and N. Ferguson, "Extent of capacity loss resulting from pavement distress," Proceedings of the Institution of Civil Engineers-Transport, vol. 158, no. 1, pp. 27-32, 2005.

[6] J. Ben-Edigbe, "Assessment of speed-flow-density functions under adverse pavement condition," International Journal of Sustainable, Development and Planning, vol. 5, no. 3, pp. 238-252, 2010.

[7] J. K. Dattatreya, A. Veeraragavan, K. Murthy, and C. E. G. Justo, "A suggested simplified system for pavement maintenance management of road network," Journal of Indian Roads Congress, vol. 53, no. 2, pp. 217-273, 1992.

[8] K. Ghasemlou, M. M. Aydin, M. S. Yıldırım, O. Karpuz, and C. T. İmamoğlu, "Investigation the effect of road surface deformations on capacity of signalized intersections by using cell transmission model," in Proceedings of the 11th International Congress on Advances in Civil Engineering, pp. 1-10, Istanbul, Türkiye, October 2014.

[9] S. B. Girimath and P. Fellow, "Pavement management system for urban roads," International Journal of Scientific and Development, vol. 2, no. 3, pp. 282-284, 2014.

[10] P. K. Gupta and R. Kumar, "Development of optimum maintenance and rehabilitation strategies for urban bituminous concrete surfaced roads," International Journal of Scientific and Technology Research, vol. 4, no. 2, pp. 56-66, 2015.

[11] S. S. Naidu, P. K. Nanda, P. Kalla, and K. Sitaramanjaneyulu, "Pavement maintenance management system for urban roads using software HDM-4 a case study," Journal of Indian Roads Congress, vol. 66, no. 3, pp. 641-669, 2005.

[12] J. B. Odoki and H. R Kerali, Analytical Framework and Model Descriptions, The World Road Association (PIARC): ISOHDM Sponsors, Paris, France, 2013.

[13] P. A. Pienaar, A. T. Visser, and L. Dlamini, "A comparison of the HDM-4 with the HDM-III on a case study in Swaziland," in Proceedings of the South African Transport Conference, Pretoria, South Africa, 2000.

[14] B. B. Reddy and A. Veeraragavan, Priority Ranking Model for Managing Flexible Pavement at Management Level, Centre for Transportation Engineering, Bangalore University, Bangalore, India, 2001.

[15] B. B. Reddy and A. Veeraragavan, Priority Ranking Model for Managing Flexible Pavements at Network Level, Indian Roads Congress ( IRC), Kochi, India, 2002.

[16] Y. U. Shah, S. S. Jain, and M. Parida, "Evaluation of prioritization methods for effective pavement maintenance of urban roads," International Journal of Pavement Engineering, vol. 15, no. 3, pp. 238-250, 2012.

[17] MoRTH, Guidelines for Maintenance of Primary, Secondary and Urban Roads, Ministry of Road Transport and Highways, Government of India, New Delhi, India, 2004. 
[18] B. S. Mathew, D. S. Reshmy, and K. P. Isaac, "Performance modeling of rural road pavements using artificial neural network, Indian highways," IRC, vol. 36, no. 1, pp. 31-39, 2008.

[19] T. F. Fwa, W. T. Chan, and K. Z. Hoque, "Multi-objective Optimization for Pavement Maintenance Programming," Journal of Transportation Engineering, vol. 126, no. 5, pp. 367-374, 2000.

[20] W. T. Chan, T. F. Fwa, and K. Z. Hoque, "Constraint handling methods in pavement maintenance programming," Transportation Research Part C: Emerging Technologies, vol. 9, no. 3, pp. 175-190, 2001.

[21] S. Terzi, "Modeling the pavement serviceability ratio of flexible highway pavements by artificial neural networks," Construction and Building Materials, vol. 21, no. 3, pp. 590593, 2007.

[22] B. B. Reddy and A. Veeraragavan, "Structural performance of in-service flexible pavements," Journal of Transportation Engineering, vol. 123, no. 2, pp. 156-167, 1997.

[23] A. Bianchini and P. Bandini, "Prediction of pavement performance through neuro-fuzzy reasoning," Computer-Aided Civil and Infrastructure Engineering, vol. 25, no. 1, pp. 39-54, 2010.

[24] H. Khraibani, T. Lorino, P. Lepert, and J. Marion, "Nonlinear mixed-effects model for the evaluation and prediction of pavement deterioration," Journal of Transportation Engineering, vol. 138, no. 2, pp. 149-156, 2012.

[25] Z. Luo, "Pavement performance modelling with an autoregression approach," International Journal of Pavement Engineering, vol. 14, no. 1, pp. 85-94, 2013.

[26] M. I. Pinard, "Factors affecting the development and implementation of pavement management systems in developing countries," in Proceedings of 2nd North American Pavement Management Conference, Toronto, ON, Canada, November 1987.

[27] IRC: 81, Guidelines for Strengthening of Flexible Road Pavement Using Benkelman Beam Deflection Technique, Journal of Indian Roads Congress, New Delhi, India, 1997.

[28] J. B. Odoki and H. G. R. Kerali, Highway Development and Management Series: Volume 4-Analytical Framework and Model Description, World Roads Association (PIARC) and World Bank, Paris, France and Washington, DC, USA, 2000.

[29] J. R. Koza, Genetic Programming: on the Programming of Computers by Means of Natural Selection, The MIT Press, Cambridge, MA, USA, 1992.

[30] W. D. O. Paterson, Road Deterioration and Maintenance Effects: Models for Planning and Management, A World Bank Publication, The Johns Hopkins University Press, Baltimore, MD, USA, 1987.

[31] IRC: 37, Guidelines for the Design of Flexible Pavements, Indian Roads Congress, New Delhi, India, 2012. 


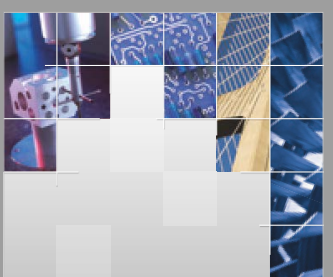

\section{Enfincering}
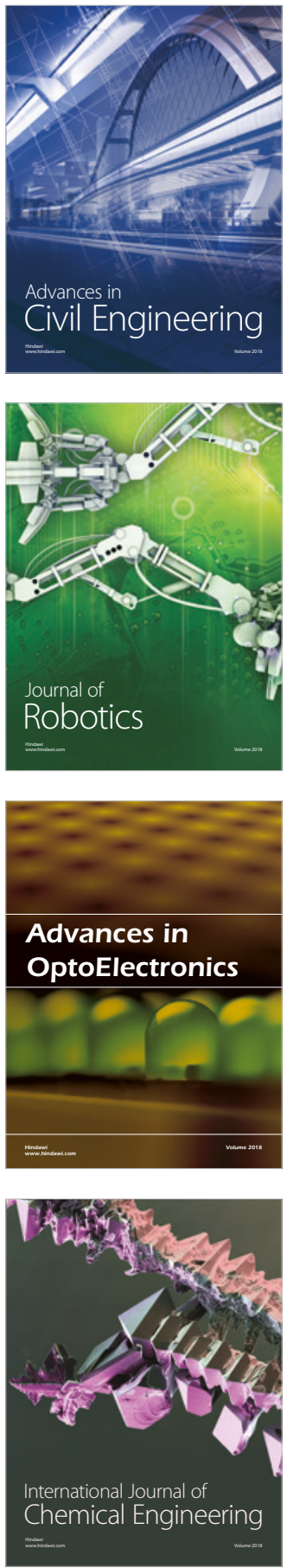

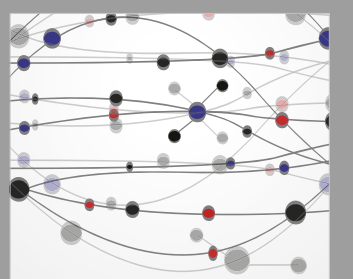

\section{Rotating \\ Machinery}

The Scientific World Journal

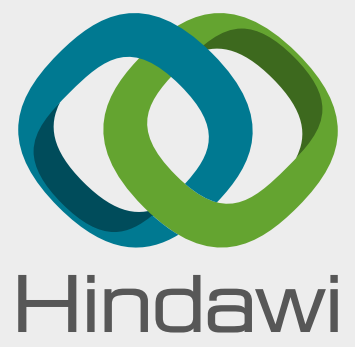

Submit your manuscripts at

www.hindawi.com
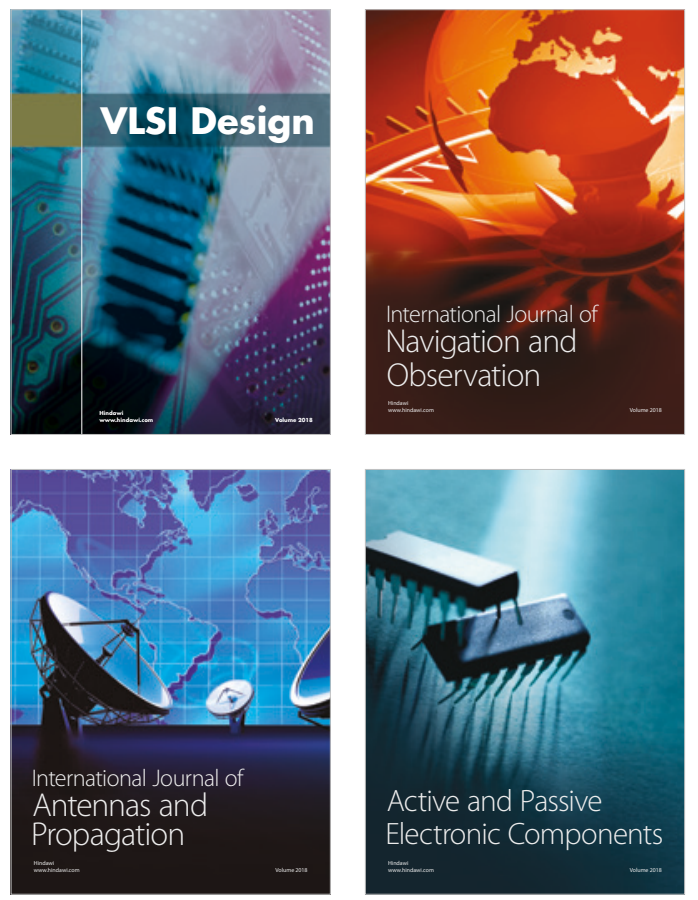
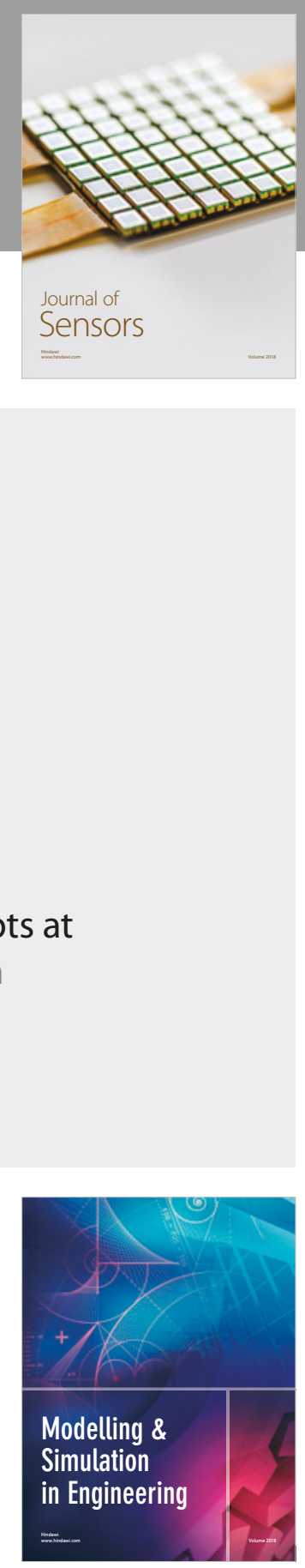

\section{Advances \\ Multimedia}
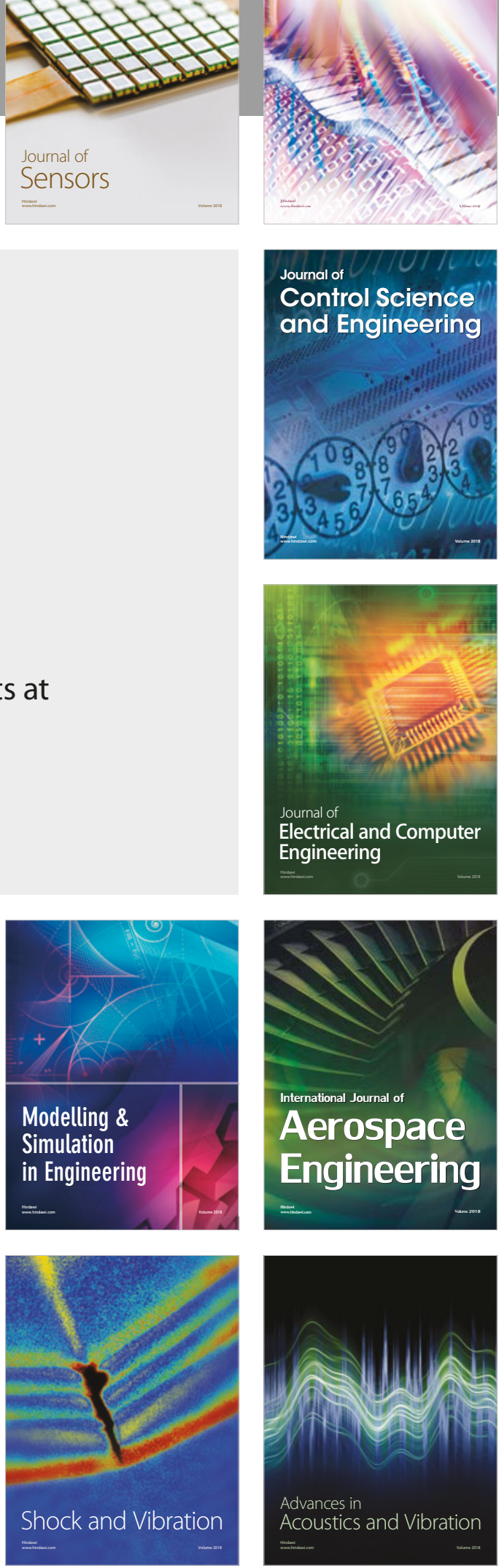